\title{
Why Reform Sometimes Succeeds: Understanding the Conditions That Produce Reforms That Last
}

\section{Citation}

Mehta, Jal, and David Cohen. 2017. Why Reform Sometimes Succeeds: Understanding the Conditions That Produce Reforms That Last. American Educational Research Journal. Forthcoming. doi:10.3102/0002831217700078.

\section{Published Version}

10.3102/0002831217700078

\section{Permanent link}

http://nrs.harvard.edu/urn-3:HUL.InstRepos:33064054

\section{Terms of Use}

This article was downloaded from Harvard University's DASH repository, and is made available under the terms and conditions applicable to Open Access Policy Articles, as set forth at http:// nrs.harvard.edu/urn-3:HUL.InstRepos:dash.current.terms-of-use\#OAP

\section{Share Your Story}

The Harvard community has made this article openly available.

Please share how this access benefits you. Submit a story.

Accessibility 
Why Reform Sometimes Succeeds:

Understanding the Conditions That Produce Reforms That Last

\author{
David Cohen \\ Harvard Graduate School of Education \\ Jal Mehta \\ Harvard Graduate School of Education
}

Final Pre-Publication Version

2017

Forthcoming in American Educational Research Journal; online first at:

DOI: 10.3102/0002831217700078 


\title{
WHY REFORM SOMETIMES SUCCEEDS: UNDERSTANDING THE CONDITIONS THAT PRODUCE REFORMS THAT LAST
}

David K. Cohen, Schools of Education and Public Policy The University of Michigan, and Visiting Professor Harvard Graduate School of Education

Jal D. Mehta, Harvard Graduate School of Education

\begin{abstract}
:
Counter to narratives of persistently failed school reform, we argue that reforms sometimes succeed, and seek to understand why. Drawing on examples from the founding of public schools to the present, we find that successful system-wide reforms addressed problems that teachers thought they had, by being consistent with prevailing norms and values, by mobilizing a significant public constituency, and building the needed educational infrastructure. We distinguish between system-wide and niche reforms, suggesting that some--particularly those seeking ambitious instruction-failed system-wide but succeeded by creating protected educational niches. We conclude with a discussion of the implications for the Common Core.
\end{abstract}

Keywords: school reform; niche; ambitious instruction; politics of education; history of education 


\section{WHY REFORM SOMETIMES SUCCEEDS: UNDERSTANDING THE CONDITIONS THAT PRODUCE REFORMS THAT LAST}

Reform of schooling has been a way of life in the U.S. Hopeful initiatives began with Horace Mann and his allies in the 1830 s and continue today. Commentary on reform has been less hopeful. Joseph Mayer Rice published devastating critiques of public schools' mechanical instruction in 1893, criticizing the schools' failure to adopt the more humane and engaging instruction that Mann and his allies had advocated. In the first half of the $20^{\text {th }}$ century researchers studied classrooms and reported that mechanical recitation remained the rule despite reformers' urging. Beginning in the 1960s researchers and journalists reported on the Kennedy and Johnson reforms, including Headstart, Title I of the 1965 ESEA, and other programs; they concluded that they failed. Though reforms continued, the sense grew that many failed. In the later 1960s and 1970s commentators began to claim that the system of public education was so sclerotic as to be incapable of serious change. Critiques of schools became more searching and proposals for change more ambitious. $^{1}$

There are deep educational problems, and reforms often fell short, but it is incorrect to say that reforms never succeeded. There have been a variety of successful reforms, some of which became so familiar that they are no longer recognized as reforms, but several others which seem to be unrecognized. Moreover, despite a few outstanding studies, there is no tradition of sustained analysis of why some reforms succeed when others fail, or of what types of reforms have succeeded and what have not, for whom, and under what circumstances. ${ }^{2}$ We aim to pursue that analysis, building on what other scholars have done and hoping to provoke more work. We want to improve understanding of education and to encourage more strategic thinking about reform. We aim to be encouraging but not naive, inviting analysis of what enabled reforms to succeed and how to improve what we know and how we act.

Our analysis is based on a thorough search of research on school reform in the U.S. We discuss a range of reforms, including those which spread widely, were institutionalized, and made significant changes to what schools did, those which tried to do such things and failed, and those which succeeded as 
niche reforms (we discuss this category below). ${ }^{3}$ We attended especially to the relationship between reform and instruction. We did not select only reforms that aimed to affect instruction, but we sought to understand the relationship between reform and instruction. One reason is that the past 25 years saw a remarkable sustained effort to design and implement reforms that aim to dramatically improve instruction, and we think that our account will improve understanding of them. Another reason for this focus is that several earlier studies seem to be at odds over whether reforms had affected instruction or other core features of schooling. ${ }^{4}$ We offer a different perspective on those accounts, which we explain as we move through the analysis.

Our analysis suggests that there are at least five characteristics of successful educational reforms. First, some offered solutions to problems that the people who worked in or around education knew that they had and wanted to solve; they met felt needs for the people who would implement them. Second, some offered solutions that illuminated a real problem that educators had not been aware of, or couldn't figure out how to solve, but they embraced the reform once they saw or believed that it would help; these reforms illuminated a problem of practice and offered a solution. Third, some reforms succeeded because they satisfied demands that arose from the political, economic or social circumstances of schooling; these reforms worked because there was strong popular pressure on and/or in educational organizations or governments to accomplish some educational purpose. Fourth, in each of these cases, reforms also either offered the educational tools, materials, and practical guidance educators needed to put the reform into practice, or they helped educators to capitalize on existing tools, materials and guidance. Less difficult reforms required less capacity building while more ambitious reforms required more. Fifth, in a locally controlled and democratically governed system of schooling, successful reforms have been roughly consistent with the values of the educators, parents, and students they affected, though this worked differently in system wide than niche versions.

Unsuccessful reforms present the flip side of these characteristics. Some offered solutions to 
problems that educators did not think they had; they met no felt need for most of the people who would implement them; they illuminated no problem of practice for many practitioners, or they offered no solutions for the people who would implement them. Still others failed either because they satisfied no demands that arose from the political, economic or social circumstances of education, because they provoked hostility from influential actors in the environment, or because they failed to convince parents and students of their value. The difficulties that several of these reforms faced were compounded by their failure to offer the tools, materials and practical guidance which educators would have needed to implement them. Several such reforms sought system-wide fundamental change in teaching and learning; they combined counter-cultural values with weak capability.

In what follows we distinguish between two different sorts of reforms. One is system-wide: it comprises reforms that aim for broad adoption within schooling. If they succeed it is partly because they had or could quickly mobilize broad support within education, outside it, or both; when they did not succeed it was partly because they did not have and could not quickly mobilize broad support within education, outside it, or both. The successful cases of such reform typically did not require deep change in practice and extensive capacity building. They were adopted and implemented rapidly and widely in part because they could work within existing educational organization and culture. The unsuccessful cases of such reform typically did require deeper change in practice and more extensive capacity building, and so could not be scaled up easily or quickly. ${ }^{5}$

Some reforms that failed system-wide worked as niche or sub-system reforms. These present a different type of success. They were smaller in scale than system-wide reforms and often counter-cultural, for they represented educational ideas and practices for which there was insufficient support system wide. If they succeeded it was because they found or created bounded educational and political territories in which they could thrive. They did so in part by defining systems that included educators, students, and a public that embraced the reform, and by mobilizing resources needed to sustain the work. ${ }^{6}$ Some niches 
are created within public education, some outside it in the non-public sphere, and some on the boundary between the two. Advanced Placement and International Baccalaureate are niche reforms that operate within U.S. public education, and Montessori has so far operated mostly outside of public education. The niches provide a means to buffer reforms from weak capability or opposition in the larger public education system. They solve the capability problem by recruiting motivated and qualified teachers, students and managers, and building sub-system infrastructure to support their work. Though some niche reforms are small or even precious, others are larger and broadly adopted. In either case, they require a more nuanced conception of scale and success.

Using this frame we contend that the story of reform is more complicated than several accounts suggest, and that there have been several successful reforms. ${ }^{7}$ The criteria that we use to decide on success are whether the reform in question moved quickly across many schools, whether it made significant changes in what schools did, whether it opened up opportunities for many students, and whether it became institutionalized as a key feature of what we know as schooling. Some changed the organization of schooling or instruction, others created different sorts of instruction, and quite a few did both. Our positive cases fit those criteria and our negatives cases do not. ${ }^{8}$

Yet the most fervent hope of many reformers - to make teaching and learning consistently more lively, challenging, and intellectually engaging - has been difficult to realize system wide. ${ }^{9}$ Unlike previous studies we find that niche or sub-system reforms had substantially more success in creating more lively, challenging, and intellectually engaging instruction, as well as a few isolated examples of districts that achieved something of that sort. The contrast between how niche and system-wide reform influence instruction is central to our analysis. In the conclusion we consider what it might take to integrate what we have learned about the conditions of successful system-wide reforms with the instructional success of the sub-system reforms, particularly with respect to the Common Core. 


\section{A SECTORAL ANALYSIS}

Understanding why reform succeeds or fails depends upon understanding the sector in which reforms operate. Niche and system-wide reforms co-exist. They are creatures of the same organizational, educational and political structures and forces, such that what impeded some system wide reforms created opportunities for some niche reforms. Four organizational factors have been particularly important in shaping these two types of reform.

One is the very open structure and weak central control in the education sector. System-wide education reforms had to win political support-to interact successfully with practitioners and publicsagain and again across many thousands of districts in many states. There is neither a unitary system nor an apolitical ministry of education that could manage the interactions, let alone manage system-wide change. Fear of federal power limited the federal government's ability to provide the tools, materials, and practical guidance needed to enact its ambitions (Cohen \& Moffitt, 2009; Cohen, 2011), and weak state governments limited their capacity to do such things. Open structure and weak central control created significant barriers to system-wide reform because to succeed they must be able to sweep through a very decentralized and weakly coordinated collection of state and local systems, and do so without having welldeveloped infrastructure (Goldin \& Katz, 2008). But the same open structure, weak central control and modest coordination presented opportunities to reformers who sought a protected niche rather than system-wide exposure. In these cases reform goals were more easily coupled with the needed infrastructure and systems to achieve them (Cohen et al., 2014; Cohen \& Hill, 2001; Childress et al., 2009; Elmore, 1997; Mehta \& Fine, 2015).

A second feature of the education sector is the remarkable vulnerability to public opinion and political pressure that has been characteristic of general and school government. Locally elected legislative and executive agencies managed most local general governments. Local school systems were governed by locally elected boards and most elementary schools were and are thought to belong to the neighborhoods 
in which they are situated (Katznelson \& Weir, 1985). Those who govern localities and schools must answer to local voters every few years for changes in taxes, curriculum, school organization or other things. Those who work in schools often are reminded that they are answerable to voters, their elected delegates, and organized interests. Beginning with the inception of public education and continuing to our own day, when reformers urged policies and practices that offended significant segments of public or professional opinion they met resistance. The most familiar example is progressive education, but the 1950s and 1960s curriculum reforms were another, and there are others. Such counter-cultural reforms had rough political sailing. Yet the same vulnerability to political pressure and public opinion opened opportunities for educators, students and parents who desired education that was quite different than what was conventional in public schools. They used the system's openness, large number of jurisdictions, weak central control and vulnerability to political pressure and public opinion to create specialized niche reforms. This approach has been especially useful for reforms that departed sharply from commonly accepted conceptions of teaching and learning.

The third important feature of the education sector is the failure of teaching to crystallize as a fullfledged profession. Professions have features that regulate and organize the quality of work: significant standards for training and licensing; social closure that prohibits those without such credentials from joining the profession; agreed upon definitions of problems the profession can solve and appropriate approaches to tackling those problems; and ongoing mechanisms to ensure that the standards of the field are applied in practice. Teaching in the U.S. has some accoutrements of professionalization but not the full form: standards for entry are low and often are evaded by emergency credentials or alternative certification; training is short and has a limited imprint on practice; daily demands to provide lessons supersede efforts to collectively improve practice; and disagreements over purposes and values impede the creation of shared language and technique (Lortie, 1975; Mehta, 2013a; Mehta, 2013b). There is little coherence and highly variable quality in teacher training (Mehta, 2013a). 
Weak professional control meant that teachers were vulnerable to lay views of education and reform, as well as to inherited patterns of practice; this was amplified by the political vulnerability of public education (Lortie, 1975). Teaching does not provide much in the way of shared definitions of problems, or materials and guidance for enacting successful solutions. Unlike other nations, teachers in the U.S. have not had the social and professional standing or political influence to be effective and strong advocates for instructional reform. Teachers unions did not give priority to the improvement of classroom work. Finally, teachers defined professionalism more as individual autonomy than shared standards of practice; systemwide reforms that did not challenge this norm fared better than those that required widespread collective learning (Schneider, 2014).

These weaknesses of teaching meant that system-wide reforms that sought significant change in practice either had to build the infrastructure and capacity required to achieve their ambitions or face weak implementation (the "hybrids" of which Larry Cuban has written), or flat-out defeat. But there is a flip side to this coin as well: while the absence of professional control frustrated reformers who would prefer to see sustained change consistent with a developing research base, it also meant that schools have been quite susceptible to ongoing lay influence. Schools are fairly porous institutions, which means that they change over time to match the broader culture that surrounds them; thus osmosis has been a powerful, if underappreciated, mechanism for change.

The fourth feature of the education sector is a sharp division between public and non-public schools. In some other nations the state system is more inclusive: schools that organize around distinctive religious or educational visions, like Catholic or Montessori schools, receive state support as long as they accept state school leaving exams or the common curriculum. Americans see such schools as non-public, yet in Holland and other countries they can be unconventional while being part of the state system.

State systems of this sort accommodate approaches to schooling that represent a reform of or alternative to the dominant system. Because the boundary of the public system is drawn quite broadly in 
these countries, public education includes many schools and systems that look like non-public schools to U.S. eyes. This also constrains inequality, for schools and systems of most sorts are available to nearly everyone, they are state supported and are more equally funded than U.S. schools. We observe a contrary situation in the U.S., where the distinction between public and non-public schools sharply limited opportunities for some reforms to gain acceptance in the public sector. Some U.S. school systems that were meant as reforms remained distant from public education despite their presence in the education sector. That enhances inequality because such schools and systems can be afforded chiefly by affluent families. To understand reform in the U.S. one must look beyond the boundaries of the state system to the entire education sector.

We deliberately define reform broadly. We include examples that we celebrate along with examples that we do not celebrate, and others that evoke very mixed feelings. What these reforms have in common is that they spread, in some cases system-wide and in others to entire sub-systems, were institutionalized, and made significant changes to what schools did - whether or not they fit with our conceptions of good schooling. ${ }^{10}$ We aim to encourage a reconsideration of how reform is understood and explained, and sectarianism would frustrate that purpose. Whether we approve of them or not, we want to understand significant efforts to depart from what was accepted as conventional at any given moment, and to figure out why some succeeded and others failed. ${ }^{11}$

\section{SYSTEM-WIDE REFORM}

We begin with successful reforms.

\section{Build Public Education}

The largest and most successful reforms were the rapid creation of systems of mass enrolled elementary education in the second half of the $19^{\text {th }}$ century, and mass enrolled secondary education during the first half of the $20^{\text {th }}$ century (Kaestle, 1983; Katznelson \& Weir, 1985; Tyack, 1974; Goldin \& Katz, 2008). 
They succeeded for two chief reasons. They satisfied demands from parents, voters and reformers that arose in public education and its environment. The demands were powerful enough to move hundreds and then thousands of schools, systems and private agencies to dramatic change (Katznelson \& Weir, 1985; Goldin \& Katz, 2008). The demands also suited educators who were eager to expand the enterprise in which they worked. The reforms also could work without deep change in the social technologies of schooling. Some reformers argued for more ambitious instruction, but education could more easily and quickly expand by using the inherited approaches to teaching, learning, and management (Cohen, 1989). It did.

Some readers may wonder why we refer to these system-building innovations as reforms: what were they reforming if public education did not yet exist? They were reforming a complicated set of educational arrangements. Though the school systems with which we are familiar did not exist, there was an education sector in which there was much education, many schools, and some systems. They came to be seen as a problem by many Americans who also saw public education as the solution (Katznelson \& Weir, 1985; Goldin \& Katz, 2008).

From one perspective these were school reforms, pure and simple. In the mid-1830s, when Horace Mann became the first Secretary of the Massachusetts Board of Education, there were many schools; there also was much education apart from schools, at home, in church, and at work. But access to formal education was quite irregular and unequal. There were plenty of places with no schools. When schools did exist many were partly pay-as-you-go, and then as now the families whose children needed school the most were least able to pay for it. Though there was some public support it was spotty and often limited. Children from poor families often attended charity schools, which struck many as stigmatizing precisely because they were set apart for the poor. Education, in school and out, varied from family to family, from school to school, from place to place, and between families and schools (Katznelson \& Weir, 1985; Goldin \& Katz, 2008; Tyack \& Hansot, 1982). 
Mann and others urged reforms that would replace unequal and insufficient access to school with state sponsored schools. They would enroll all children at public expense, solving part of the unequal access problem. They would solve two other parts of that problem by offering all students a common curriculum and enrolling students from many different circumstances in the same schools. When reformers wrote and spoke of "common schools" they referred to these three elements of equal education (Katznelson \& Weir, 1985). It began a tradition of reform, still in progress at the post-secondary level, which expanded and equalized access to formal education.

From another perspective the creation of these same state-supported elementary schools was a cluster of political reforms. As Ira Katznelson and Margaret Weir (1985) showed in Schooling For All, one key to that cluster was broad access to the vote. By the 1830 s men who were free, white and 21 could vote. That was a major reform of U.S. politics: voting had been the province of the well to do, and those privileged men had seen the U.S. as a republic in which there was limited suffrage. But as access to the vote opened in the 1820 s and 1830 s it was becoming a democracy. By opening citizenship much more broadly and earlier than in Europe, the U.S. created what we now call political buy-in. Ordinary men could see themselves as important members of the body politic, and thinking that their children would be better off if they were better educated they voted to create schools and tax themselves to support them. The franchise was seriously limited and shadowed by the exclusion of African Americans and women, but it was broad enough to make state supported elementary schools quite popular outside the South.

Another political element of this reform was to build schooling from the bottom up; state and federal support and legitimation were important but schools were locally initiated, locally governed, and locally operated. School government was one of the new nation's most extensive forms of political democracy. Still another political element, one of the most consequential but least appreciated, was that by creating public common schools the state took on a new assignment: mold the minds of future citizens. This was a remarkable innovation, for no nation-state (revolutionary France was a brief exception) had 
previously undertaken to systematically shape the minds of its citizens through a system of state-supported schools. In the U.S. this seemed constructive, since reformers argued that schools would build democracy by teaching students what they needed to know to be intelligent citizens. But this was a large new territory in which there were some deep problems and are deep disagreements.

To build public elementary school systems was, for reformers and many citizens, to build a democratic state and people. It was done not just because the common school crusaders wanted it but because many families and voters were keen for their children to be educated, were willing to press politically in thousands of localities to create or expand schools, and to pay with their taxes. Some new public agencies even took over existing schools, diverting students from what we would call private schools to the new public systems. On all of these counts, state-sponsored elementary schooling was a major political and educational reform.

This reform meets our criteria for success at scale. It offered solutions to problems that the people who worked in or around education knew that they had and wanted to solve; it met felt needs for the people who would implement it. It was not just the work of reformers and government but a social movement in which there was broad popular participation. It also reflected a huge social change, in which informal education in the intimate settings of home, work and church was partly supplanted by statemandated school. The reform was impelled by forces that arose outside of schools, but was roughly consistent with the values of the educators, parents, and students it affected.

The reform was a success. Elementary schools multiplied and enrollments increased dramatically during the last half of the $19^{\text {th }}$ century, and hundreds of thousands of children, who otherwise would not have had instruction, did. ${ }^{12}$ Yet in two other senses it was not a success. African-American students were excluded from many communities and schools in the North, and almost all of their fellows in the South were entirely excluded from schools. In addition, though teaching and learning spread with astonishing speed and scope, classroom work typically remained traditional and mechanical. Horace Mann's vision of 
schools bringing learning to America's children was realized, but his hope for intellectually ambitious and humane classroom work was not.

The reform of secondary education during the first half of the $20^{\text {th }}$ century was similar. Secondary education was modest in scale and selective in the late $19^{\text {th }}$ century, but by the 1920 s it was well on the way to mass-enrollment. The heart of this reform was greatly expanded democratic access to school. As with elementary schools there were systems or elements of systems that had to be changed or replaced. One was the existing selective and modestly enrolled secondary schools. Another was the academies, which often were selective, sometimes charged fees, and operated on a relatively small scale. Another was the secondary departments that were tacked on to some elementary schools. Still another was the extant secondary curriculum, much of which was quite traditional, with ancient languages and academic subjects that many reformers claimed would be useless to students going to work in a rapidly changing economy in which employers would prize practical knowledge (Goldin \& Katz, 2008).

Secondary schools changed with phenomenal speed; after 1890 secondary enrollments at least doubled every decade (Powell, Farrar \& Cohen, 1985). By 1920 the mass enrolled schools had new and differentiated curricula. Adding the new curricula required innovation in the types and content of school courses and school organization, but did not require transformation in the social technologies of schooling; secondary education could greatly and quickly expand using inherited methods. New courses had to be devised and offered, but some were only less demanding versions of existing courses. Others were less familiar but required only people who knew bookkeeping, secretarial work, and other vocational subjects to teach them. The growth of high schools and the expanded curriculum had huge instructional effects, in the sense that hundreds of thousands of children, who otherwise would not have had secondary instruction, did. But those instructional effects were possible precisely because they required no major change in pedagogy, let alone greatly improved knowledge and skill for teachers. 
As with elementary schools, this reform met our criteria for success at scale. It offered solutions to problems that the people who worked in or around education knew that they had and wanted to solve; it met felt needs for the people who would implement it. It was not just the work of reformers and government but a social movement in which there was broad popular participation (Goldin \& Katz, 2008). Both elementary and secondary reforms were driven by pressure on local governments from parents who wanted more economic opportunity for their children, citizens who wanted to boost their communities by building schools, educators who were keen to expand their domain and reformers who wanted to improve American society. Because there were thousands of communities in which schools were locally governed, pressure from parents, educators and boosters was essential; reformers could not have done it alone (Goldin \& Katz, 2008). The reform also offered the educational tools, materials, and practical guidance educators needed to put the reform into practice, and helped them to capitalize on existing tools, materials and guidance. The reform also was roughly consistent with the values of the educators, parents, and students it affected.

The reform was a remarkable success. Secondary school enrollment rose from approximately 10 percent of the age-eligible cohort in 1910 to more than 70 percent by mid-century. ${ }^{13}$ But this success also was limited: schooling grew without major change in instruction, and African-American enrollment lagged far behind whites in the North, while many black children were excluded from high school of any sort in the South (Anderson, 1988).

\section{Schools For The Freed People}

Before the Civil War ended but as it became clear that the South was losing, a spontaneous black social movement to educate the former slaves erupted. This crusade for common schools was more spontaneous and less led by organized reformers than the renowned crusade that began in New England. But like the Northern movement it depended on popular demand, popular willingness to organize schools and pay for them, and on agencies that could help with organization, funding and legitimation. 
Slaveholders had withheld education from their chattel. They understood that in literacy lay a measure of independence and therefore liberty and power, but racial slavery in the U.S. depended on enforced ignorance to curtail the slaves' liberty and power. Slavery also depended on slaveholders' monopoly of violence and was rationalized by a racist ideology of African intellectual inferiority. On both counts, state-compelled ignorance was a foundation of slavery. Southern states legislated fines and other penalties for whites who educated slaves, and slaves who tried to learn to read and write, or who taught others, were punished severely, including torture and death.

Whatever else this regime did, slaves learned that education was a key to liberation. Many ran great risks to learn to read and write. Then, as federal troops began to move into the South in 1863 slaves freed themselves and created schools. As the Union armies began to accept black recruits the new soldiers organized small improvised schools within their units in order to learn to read and write and teach others. As the slave regime collapsed in rural areas and cities were freed from Confederate control, blacks started schools. Throughout Reconstruction the Federal armies were essential to black liberation, including the Freed people's crusade to school themselves (Anderson, 1988; Butchart, 2010).

Once the war ended the crusade took off. It was quite spontaneous and initially uncoordinated by any agencies. Schools of all sizes and descriptions sprang up across the South: some enrolled children, some enrolled adults, and many enrolled both. Some teachers were well educated while others had only rudimentary literacy, but so great was the need and so strong the demand that even the most rudimentary schooling was welcome. Many were single classroom affairs, while others had several classrooms. Class size varied from 30 to $60,70,80$ and more.

The crusade did acquire some organization. African-Americans created state and local educational associations. The Freedmen's Bureau in the War Department in Washington hired representatives to ride circuit in the South, visit schools, offer help, and advise educators about how to apply for Bureau funds. The Bureau paid for some teachers and materials, though the demand regularly outstripped its funds. 
Northern missionary associations sent money, teachers and books. As blacks were elected to state legislatures and executive agencies, some state governments helped (Anderson, 1988; Foner, 2002).

The black crusade continued into the mid-1870s. Solid estimates of schools and their enrollments are difficult to come by because the movement was spontaneous, often local, and not tightly managed. Few states made much effort to collect data on the number of schools, teachers and students. By 1870 there were more than 1,000 schools for freed people.

Like the Northern crusade this was a social movement to broadly spread access to schooling, but unlike the Northern crusade it aimed to overturn state-maintained denial of schooling and was supported by federal troops and federal policies. The Northern crusade faced little resistance, and though it was a departure from past political practice it was not a revolution. The Southern crusade was exactly that, and it succeeded in several respects. For one thing, any increase in black literacy gained the former slaves a measure of independence and therefore liberty and power. Many African-Americans learned at least some of the things that the slave system had denied them, and black literacy increased quite dramatically; by $190056 \%$ of adult blacks were literate, as compared with $20 \%$ in $1860 .{ }^{14}$ For another, several hundred African-Americans became teachers, school heads, members of educational associations and educational officials in the post-war decade, and many went on to serve in state and local elected offices (Anderson, 1988; Foner, 2002). Still another was that the African-American crusade led some whites and many blacks to see a need for government action. Once Reconstruction was well under way several states established state school systems that would be open to all students, and those systems began to bring free public education to the South for the first time (Anderson, 1988; Foner, 2002).

The black crusade for schooling satisfies our criteria for success on several dimensions. It was system-wide in five respects: It aspired to create universal schooling; it aimed to open schooling to black and white children; it created many schools throughout the South, including some that were integrated; and it greatly expanded the number of African-American educational and political professionals. Each of 
these was part of the foundation for later educational system building in the South (Anderson, 1988; Foner, 2002). The reform met our criteria for success at scale in several other respects as well. It offered solutions to problems that the Freed People and others who were engaged with their cause knew that they had and wanted to solve. It met felt needs for the people who would implement it. It was not chiefly the work of reformers and governments but a social movement in which there was broad and intense popular participation. The spread of schooling for the Freed People also reflected a huge social change, reversing a situation in which education of nearly all sorts had been denied to them. The reform did not offer all of the educational tools, materials, and practical guidance that educators would have needed to put the reform fully into practice, because so many of the spontaneous teachers, by their own accounts, did not have the knowledge they would have needed to help their student learn everything they wanted to learn. But it did depend on the use of those tools that were available, and it did enroll and educate many thousands of former slaves. That part of the reform's success owed a good deal to the students' commitment to learning whatever they could, as well as to educators using whatever knowledge, existing tools, materials and guidance they had. This reform's success also owed a great deal to so many of the students having been entirely illiterate, so that even learning the alphabet, which was all that some teachers knew, was precious progress (Anderson, 1988). The reform also was deeply consistent with the values of the educators, parents, and students it affected.

Though this reform was a signal successes given previous Southern history it soon became precarious, for unlike the Northern crusade this one was resisted fiercely and violently. The resistance arose not from teachers or other educators but from whites who intended to overturn Reconstruction in order to re-establish white supremacy. In our analytic frame, this was rejection of reform from sources in the environment of schooling. "Redeemers" - former slaveholders and others who sought to re-establish slavery or something like it-began campaigns of terror in response to the movement for black education almost as soon as it began. They burned black schools, ran off and murdered teachers, principals and other 
black local and state officials. As federal troops withdrew through the late 1860 s the Redeemer movement gathered force, Reconstruction began to wane, and the black crusade for schooling slowed. The new state school systems had been integrated by law, but by the end of the $19^{\text {th }}$ century white-dominated governments in the region had closed some of them down, reduced funding in others, and turned those that remained into parts of the racially dual school system. The crusade for black schooling was an impressive reform in several respects, but unlike any of the others that we discuss here, it was only one chapter in a long and bloody struggle over schooling for African-Americans.

\section{Age-Grading, Early Standardized Testing, and Extra-Curricular Activities}

No other system-wide reforms matched the ambitions and scale of public elementary and secondary schools, but several other reforms gained system-wide adoption and implementation.

One was graded schools, and another, closely related, was graded textbooks. In the mid-19th century, when elementary school expansion began in earnest, students of many different ages shared the same teacher, room, and benches. That might work in small schools with modest enrollments but it could be chaotic when enrollments climbed with no way to sort the young crowd into manageable groups. If schools were instead organized by grades, and students' age and/or educational accomplishment were used to group them for instruction, the difficulty of teaching many students of different ages in the same space was eased. Some educators had argued for this reform earlier, but the idea seemed to take off when growing enrollments convinced educators that graded schools could help them to manage. Viewed from the perspective of 2017 this might seem a ho-hum reform, but for a nation that had little experience building school systems, no experience with mass enrollment, skimpy budgets and an acute shortage of skilled teachers and school managers, graded schools were a big change. They spread quickly in settled areas but one-room schools lived on in the rural U.S. until the mid- $20^{\text {th }}$ century, partly because the thinlysettled population did not create pressure to change school organization. ${ }^{15}$ 
Several other reforms were widely and rapidly adopted in the early $20^{\text {th }}$ century. Norm-referenced standardized tests, which were invented then, were marketed as scientifically valid measures of students' academic ability and/or achievement. When students scored poorly that was not viewed as an indication of the need for enriched instruction, but that such students would fare better with less demanding academic work. The tests and these accompanying ideas also helped to propel and legitimate the spread of ability grouping in elementary schools, which convinced many teachers that more "homogenous" grouping of students greatly eased the demands of their work.

Another example is the growth and institutionalization of extra-curricular activities. As high schools became mass institutions that enrolled many adolescents who were seen as indifferent to academic work, educators sought to "motivate" and hold them in school. Extra-curricular activities, including athletics, music, drama, newspapers, yearbooks, and various student clubs, seemed a promising solution which in addition could train students in life skills that were not part of traditional subjects. This reform was popular with students, who found varied outlets for their energies and appreciated the opportunity to take more leadership in extra-curricular activities, with teachers who voluntarily affiliated as sponsors of clubs and activities that they enjoyed, and with parents and community members who could attend these events and for whom the more active approach seemed more similar to the kind of non-academic world in which they lived. In a relatively short period of time, between 1910 and 1930, extra-curricular activities went from rare to becoming part of almost every school across America. This reform also met our criteria for success. Extra-curricular activities had broad support within and/or outside of schooling (Lynd \& Lynd, 1929; Hollingshead, 1949). The reform was relatively easy to implement, in part because it required no change in the core technology, but simply added activities that either could be managed largely by students (as with chess clubs) or by teachers or others who volunteered. These activities also solved problems that the implementers recognized and wanted to solve (Powell, Farrar, \& Cohen, 1985; Lynd \& Lynd, 1929; Hollingshead, 1949). 
All of these reforms were successful in the sense that they were adopted broadly and changed schools and school organization significantly, but the reasons for their success differed in some respects. The creation of elementary and secondary systems was driven by pressure and support from the environment of schooling and educators, and they solved problems that parents and citizens could readily identify. The rise of black schools in the South similarly benefitted from a strongly identified need and a powerful popular movement. Graded schools and textbooks changed schools' organization and instructional materials; they solved problems that some teachers and school heads knew they had, and their existence persuaded other teachers and school heads that they had a problem that the reforms could help them to solve. Extra-curricular activities solved a problem associated with the onset of mass enrollment, they required skills which teachers possessed, and they were popular with students, teachers, parents, and the community. Though each reform significantly changed schooling, and several added significantly to the pool of instructional knowledge and skill, none required deep change in existing teachers' knowledge, skills and dispositions. Elementary and secondary school systems could grow rapidly by adding to the pool of knowledge, skills and dispositions while not requiring existing teachers to change what they knew or could teach.

\section{Change by Osmosis: Liberalization in the Treatment of Students}

Some reforms are engineered while others are driven by change elsewhere in society. One example of the latter is the sea change in how students are treated. Accounts by Joseph Mayer Rice and others of turn of the century schooling suggest that schools were austere and highly regimented places, where students were expected to recite, where corporal punishment was commonplace, and where adult authority was a given (Rice, 1893; Stevens, 1912). All of these dimensions have changed fairly dramatically-teachers today, on the whole, treat students with more respect, corporal punishment is outlawed in most states, ${ }^{16}$ and adults, sometimes to their frustration, find that their authority is often more negotiated than conferred (Grant, 1988). There are still class differences in how students are treated- 
upper track students and affluent schools are more likely to feature opportunities for student initiative, and working class and poor students are more likely to be asked to comply with directions (Anyon, 1981; Oakes, 1985) - but, even in high poverty schools, there is less corporal punishment, less formality, and less draconian student-teacher relations than there was a century ago. One experienced observer, commenting on this point, wrote that our account "....reminded me of the fifth grade classroom I visited a few weeks ago. The fifth graders were sipping from their water bottles, the teacher dressed in jeans and blouse, had coffee on her desk; three kids sat on sofa in back of the room working on their tablets and the rest of the class, sitting in small groups around a table."17

These changes result more from changes in culture than in policy. American society changed enormously in a century, with liberalized views of child-rearing, decline in support for corporal punishment, growth of rights-oriented discourses in the 1960 s and beyond, increasing commitment to racial equality, and more. Because schools are relatively porous institutions with a weak professional culture, value shifts in the larger culture can shape changes in schools. To consider just one example, when one of the authors (Mehta) attended high school in the mid 1990s, there was not one openly gay student in his progressive Mid Atlantic independent school. There were no clubs for gay students, no assemblies, no support groups, no public recognition of any kind. Today, about 20 years later, as the country's view of homosexuality and gay marriage rapidly evolved, that school and many others have some form of gay-straight alliance, students bring same-sex dates to proms, and large majorities of young people favor gay rights. This change, consistent with our overall story, required no substantial change in teacher's pedagogical knowledge, but is consistent with the changing broader values of the schools' ecosystem. Change by osmosis is not taught in policy courses, but it can be a powerful form of system-wide change.

\section{UNSUCCESSFUL SYSTEM-WIDE REFORM}

There is no shortage of such reforms; we consider a few cases to clarify their key attributes. 


\section{Progressive Education}

Perhaps the leading case in point is child-centered instruction. Though this reform is commonly attributed to John Dewey, by the time he began to write about schools the idea had been circulating for nearly a century. Horace Mann was the first highly placed U.S. advocate; his seventh annual report argued that for excellent teachers "The knowledge they (pupils) already possess about common things is made the nucleus around which to collect more; and the language with which they are already familiar becomes the medium through which to communicate new ideas, and by which, whenever necessary to explain new terms (340)." Mann's ideas, which probably owed a good deal to Pestalozzi, found some important advocates through the $19^{\text {th }}$ century, Dewey being the last and most consequential.

In How Teachers Taught, Larry Cuban (1984) investigated what inroads child-centered instruction made in mainstream $20^{\text {th }}$ century classrooms. Cuban did the study after the fact, so he relied on photographic and other documentary evidence about classroom organization. He judged Progressive Education chiefly in terms of the extent of child-centeredness, and he judged that in large part by the arrangement of classroom space. He concluded that this reform made modest progress in urban classrooms, and that the result was hybrids of traditional and novel practice.

Larry Cuban's account makes sense, for child-centered instruction would have been a profound change in teaching and learning, even if most educators had desired it. ${ }^{18}$ But desire alone would have been insufficient to close the gap between conventional didactic and child centered instruction. Teachers would have needed extensive opportunities to be convinced of the value of new ways of teaching, and to learn how. Most teachers and school managers would have needed new educational materials, a very different sort of education for practice, and sympathetic and well informed supervisors to help them to learn a very different approach to instruction. There was little pressure from teachers for child-centered education; the proposals solved problems that reformers saw in schools, but they solved no problems that most teachers saw. There also were few of the resources that might have helped child-centered schooling to 
work system-wide. Mann and his allies had urged the transformation of instruction, but they did not devise the intellectual structure, content for schooling, and systems of teaching and teacher education that would have helped educators to make the change. Dewey also was longer on intellectual prescription than on means to realize it system-wide. There was little that approached a well-developed design for teaching and learning that teachers could use to frame child-centered instruction, help them to devise lessons, and to judge the quality of students' work. These would have been important elements of the capacity building to which we referred earlier, but most reformers offered principles - work with real life or authentic problems, begin where students are, capitalize on what engages students, and the like - and explanations of why the changes were desirable, rather than detailed programs for practice. (Cohen et al. 2014).

Equally important, there was very little pressure on schools for child-centered schooling. Every study that probed what parents and students wanted from local schools reported little pressure for such things. The two classic accounts, Middletown and Elmtown's Youth, found that parents were more interested in their children's social and vocational success, and were much more engaged with school sports and other extracurricular activities than with academic work (Lynd \& Lynd, 1929; Hollingshead, 1949). ${ }^{19}$ Most students shared these views and preferences, and local educators responded with undemanding academic work and a growing investment in extracurricular activities, sports, and vocational education. ${ }^{20}$ These difficulties are the reverse side of the criteria for success that we discussed earlier. Though it was not a successful system wide reform, child-centered schooling had some success as a niche reform, a point we take up below.

\section{0s and 1960s Curriculum Reforms}

These grew in part from discontent with aggressive anti-intellectualism in public education in the 1930s and 1940s, and in part from reactions to the successful 1950s launch of the Soviet Sputniks. Reformers urged more academic content, less life-adjustment education, and more attention to the best 
and brightest. Some of the reformers were distinguished professors in leading universities while others were less visible, but many urged that academic work be revised so that students' lessons were modeled on the work that scientists and humanists actually did, rather than on pale, learned-by-rote summaries. If students had to solve problems as real mathematicians did, if they had to make inferences from primary sources as real historians did, they would be more engaged and their learning would carry them much further into the subject. ${ }^{21}$

There were several barriers. The reform did not solve a problem that most teachers thought they had, and it would have greatly enhanced the difficulty of their work. The new curricula sought to turn instruction from humdrum teacher-centered memorization into intellectually challenging studentcentered problem solving (Sarason, 1971). Yet there was no strategy to build the capacity to solve that problem, nor was there a well-developed system to support teachers' use of the new curricula. In fact, one leading academic, Jerome Bruner, resisted suggestions that he and other developers of Man A Course Of Study develop such a system (Dow, 1991). There was nothing like the instructional systems that several Comprehensive School Reform Designs devised three decades later, which we discuss below. There were summer workshops for teachers who wanted help and could pay or get their districts to pay, but that did not reach many teachers in the general, commercial or vocational curricula, where most high school teachers and students worked. Richard Elmore argued that this reform successfully mobilized engagement from a small minority of already committed teachers, but could not make the transition to system-wide success because the reformers did little to engage the large majority of teachers who were not already committed or to help them to learn to use the new curricula effectively (Elmore, 1996).

Nor was there popular pressure for the reform. In fact, the new curricula provoked resistance, for parents often were puzzled or angry when their children asked for help with math homework that the parents did not understand. Few parents had studied set theory and other features of the new math when they were students. Teachers were upset when they had to teach mathematics that they did not 
understand, and were given little or no help to learn (Sarason, 1971). When politicians heard about the central role of evolution in Man A Course Of Study (MACOS), some responded angrily. Conservatives in the U.S. Congress mounted a campaign against MACOS, cut the NSF appropriation and told the agency not to sponsor such work (Dow, 1991). Researchers later reported little evidence of any improvement in students' academic performance that could be linked to the curricula (Welch 1979). In the late 1970s Robert Stake

and Jack Easley studied the persistence of the new curricula in high schools but found few traces apart from the upper reaches of the high school curriculum (Stake et al., 1978).

The curriculum reforms encountered problems familiar from child-centered schooling. The reformers stood outside the system and saw real problems, but few who worked in schools saw the same problems, nor did they see the reform as something that would solve other problems that they faced. Worse, both reforms would have greatly complicated teachers' work, but neither offered schools and teachers substantial help with implementation. Absent strong and sustained external pressure to implement either reform, there was nothing, in a locally controlled and popularly governed system, that would prompt large-scale change. It did not materialize.

\section{NCTM AND OTHER MATH STANDARDS}

In 1989, the National Council of Teachers of Mathematics published standards that were

intended to reshape mathematics teaching. The standards argued that most American students were exposed to fairly superficial and procedural versions of mathematics, and that teaching should be recast to be more conceptual and enabled students to understand the reasons underneath mathematical operations. The document represented the official position of the NCTM and was widely covered in the educational and the national press. Subsequent federal academic standard setting efforts (IASA and NCLB) created opportunities for advocacy of NCTM, and several innovative math curricula followed suit. There have been very nearly three decades of advocacy and support for the reform of mathematics instruction from the professional math community. 
Since no studies that presented a comprehensive account of mathematics instruction prior to the reforms, there is no way researchers could determine how or how much math instruction changed. Recent research thus has sought to discern the extent to which instruction did or did not correspond to what the reforms urged. No studies report that math instruction is generally consistent with the practices that the NCTM and other standards urged (Kane \& Staiger, 2012). ${ }^{22}$ Researchers report that some teachers use more demanding curricula in math teaching, and that some open up classroom discourse as NCTM and other reformers urged. But the studies reveal that most classrooms were teacher-centered and that most math instruction was procedural, both common features of the teaching the reforms tried to change. ${ }^{23}$

One recent study took a more complex approach to studying elementary school math instruction. It focused on five urban districts that had tried, with varying degrees of intensity, to promote the sorts of math instruction that the math reforms urged (Hill et al., 2017). On the one hand the researchers reported that the format of instruction was mostly quite traditional "... direct instruction dominated in our sample; in $61 \%$ of segments, teachers entirely controlled the delivery of mathematical content, including conducting presentations of material, going over homework or problems, launching tasks, or supervising student work time...Whole-class discussion (which required students to comment on one another's mathematical ideas or solutions rather than responding solely to the teacher) occurred in some or all of only 5\% of segments (Hill et al., 2017: 22 ).

But the researchers also reported “...a significant amount of meaning-oriented instruction occurring in classrooms." (Hill et al., 2017: 24). "Over one quarter of segments contained either an explanation for why a procedure works, why a solution method makes sense, why an answer is true, or what a solution means in the context of the problem" (Hill et al., 2017: 23): Thus if the content of instruction moved in the direction that math reforms urged, the format of instruction mostly remained as it had been, so that the new "...meaning [was] primarily conveyed via direct instruction" (Hill et al., 2017: 24). Though they make no firm causal attributions, Heather Hill and her colleagues argue that if one studies instruction 
in ways that capture some of its complexity, one can detect at least some of the complicated and often seemingly disjointed ways in which educators can respond to reform. The math standards did not have the system-wide uptake in practice that reformers urged, but in local districts that sought to respond to the reforms there was some uptake.

This case particularly reveals the absence of professional infrastructure, for the new standards were not accompanied with widely available new materials, tools, guidance, school organization and professional development that did seem to support moderately effective implementation in some districts (Hill, et. al., 2017). Hence this reform did not succeed on the criteria that we already noted. It had support from one important disciplinary organization and some governments and other NGOs, but no broad support within schooling. It lacked any serious support outside of schooling, and that was particularly telling, because the standards would be quite difficult for most teachers to implement. Moreover, they solved no problems that most teachers who would implement them, or parents recognized or wanted to solve.

\section{NICHE REFORMS}

Some reforms that failed in the mainstream succeeded in niches. Others took shape only in niches. We explain what such reforms are, how they work, what we mean by "niche," and what our analysis implies for understanding reform. We discuss several non-public as well as public niche systems, because the non-public systems aim to improve the quality of schooling, or educational opportunity, or both. Like public school reforms, they seek to improve schooling in the education sector. ${ }^{24}$

As far as we know the idea of niche has not been used to discuss varieties of schooling or school reform, so we want to be clear. There are several familiar definitions of niche, including "...a specialized segment of the market for a particular kind of product or service..." or "...denoting or relating to products, services, or interests that appeal to a small, specialized section of the population." 25 The latter implies a dynamic relationship among the occupants of a niche, the nature of the niche, and the environment, which 
turned us to ecology: "Niche construction is the process in which an organism alters its own (or other species') environment, often but not always in a manner that increases its chances of survival....Several biologists have argued that niche construction is as important to evolution as natural selection (i.e., not only does an environment cause changes in species through selection, but species also cause changes in their environment through niche construction). This back-and-forth creates a feedback relationship between natural selection and niche-construction: when organisms affect their environment, that change can then cause a shift in what traits are being naturally selected for." ${ }^{26}$

Niche reforms are school systems that add space in the education sector by defining a novel and specialized mission and mobilizing resources to support and sustain it. Resources include students, teachers, families, funds and educational programs; these often yield political influence. Niche reforms change the environment by increasing the population of systems and diversifying organizations, missions and programs. Some draw resources in from outside the sector, but others subtract resources from the sector. They have a dynamic relationship: creating a niche changes the sector, just as changing the sector's policies can affect niche reforms. ${ }^{27}$

\section{Progressive Education}

Despite this reform's failure to make deep inroads in the mainstream, Progressive ideas and practices survived and even thrived. A small band of Progressive schools had long and productive lives: the Bank Street College School, Shady Hill, and Francis Parker are examples, among others. These schools mobilized the capability for an unusual approach to schooling by recruiting and educating teachers who embraced Progressive values. Given resistance and little capability to transform instruction system-wide, selective recruitment and protected choice was the alternative. Since parents had to pay tuition Progressive education was available chiefly to middle and upper-middle income families.

Teacher education programs at Bank Street College, Wheelock College, and Lesley University, among others supported the schools. These organizations and others kept the ideas and practices alive 
with resources that included common commitment, non-public funding, and solutions to the capability problem. They constituted a protected sub-system in which counter-cultural ideas and practices could survive and thrive, absent broad, strong, and persistent pressure for Progressive education from parents and educators in the mainstream. These conditions limited the scale of reform while protecting it from the problems that Progressive education faced in the mainstream.

Some examples of how Progressive education was able to succeed for a time even in the larger environment highlight the strengths of the niche version. Vito Perrone, then Dean of the School of Education at the University of North Dakota, led a statewide effort to teach teachers how to work as Mann and Dewey had urged. Lillian Weber did something similar in New York City in several decades' work with teachers in the public schools (Silverman, 1970). Jesse Newlon led an effort to bring Progressive ideas and practices to Denver in the 1920s and 1930s. In these cases and perhaps others, strong leadership, time, and weak opposition enabled educators to bring Progressive practice to local segments of the mainstream (Cuban, 1982). Yet when the leaders left support for the reform weakened. Leadership is important, but in the political design of U.S. schooling it is no substitute for sustained support from educators, parents and others who want the reform.

\section{Montessori ${ }^{28}$ and Waldorf}

These non-public niche systems offer educational programs that diverge quite sharply from conventional public schools. Each is the U.S. version of an international system, and they created structurally similar niches. Each offers a quite distinctive culture and pedagogy, and they recruit parents and students who embrace each system's educational vision and program. Each comes with a welldeveloped instructional system, with means to recruit faculty and students, professional education, and methods of quality control. Montessori AMI certifies its teachers and programs, which gives it powerful mechanisms to ensure knowledge of methods and quality control. These systems sustained themselves by recruiting loyal clienteles and funding through tuition-they served children of middle and upper-middle 
income families-and philanthropic donation (Cosentino, 2005; Cosentino, 2006; Cosentino, 2009). Though Montessori might seem precious it operates at a growing scale; there now are more than 4,000 private Montessori schools in the United States, of which only about 230 are certified by Montessori Global. Unlike some non-public niche systems, Montessori has been seeping into public education; more than 400 public schools now self-identify as Montessori.

This discussion might convey the idea that niche reforms are either small or so far from the mainstream that they can only survive in small and well protected bubbles. That turns out to be untrue.

\section{Advanced Placement and International Baccalaureate}

AP was created after World War II by a small group of private schools and elite universities in collaboration with the Ford Foundation, and was opened to public high schools in the mid 1950s. AP was counter-cultural, but unlike the curriculum reforms, it thrived. One explanation is that it helped to solve a problem that had worried some educators for decades: how to respond to differences in the demand for academic work from parents and students in public schools that were mass enrolled and democratically governed. The secondary curriculum had been differentiated by assumptions about students' academic ability and vocational destinations since the early $20^{\text {th }}$ century, but the demand for high-end secondary schooling grew as America prospered in the 1950s and 1960s, secondary enrollments increased and higher education opened to more students. High school teachers with strong academic orientations welcomed opportunities to teach students with academic ambitions. The parents of such students often agreed, as did some school managers and school board members, especially in affluent urban and suburban neighborhoods. University professors who liked the idea of more demanding work in high school joined the AP system, working with high school teachers to write questions and grade students' exams. There was, then, pressure and support for this counter-cultural reform within and outside public education; AP, like other niche reforms, was able to mobilize the professional, social and political resources to sustain a subsystem that could not have been viable system-wide. This reform did require significant change in 
instruction: AP had more demanding work and a faster pace than most general or commercial classes, but this was a subject centered rather than student centered reform. There were no other instructional changes that would have required extensive capacity building. Teachers joined because they wanted the work, and AP teachers still lectured, students still took notes, and if there had been photographs Larry Cuban would have seen teacher-centered classrooms.

International Baccalaureate (IB) is broadly similar. It began in 1960s Europe as reformers sought intellectually demanding upper secondary academic curricula and credible college entrance preparation. The clients were families, many expatriates, who sought opportunities for their children to enter first-rate universities. The program grew slowly for several decades in Europe, North and South America, Africa, the Middle East and Asia. It also expanded to elementary and middle schools. IB recently has been adopted in high-poverty minority enrolled U.S. high schools, where it operates chiefly in public schools. 1,623 public schools had an IB program in 2012; about half were schools that receive ESEA Title I funds, and slightly more than one-third were high-poverty schools. ${ }^{29}$

AP and IB are classic niche reforms. They had clear missions and clienteles, and dealt with bounded segments of secondary education. Though counter-cultural they were feasible because engaged students and teachers could select in, solving the capability problem partly by recruitment and mutual choice. Each also drew resources into public education from outside the K-12 sector, including universities, professors, and private foundations. Though both recently expanded into new territory they have been politically feasible because there was demand inside and outside of the schools, and protection from the problems of system-wide implementation. The two reforms thrived as they departed from conventional instruction.

AP and IB are large-scale operations. More than 21,000 high schools in the U.S. have AP programs ${ }^{30}$ and more than 30 percent of high school graduates take at least one AP exam. ${ }^{31} \mathrm{IB}$ operates in more than 1,600 U.S. public schools. The programs are growing to include more students from minority groups and poor communities. Whatever else they may be, they are not small and precious; they combine elements 
of educational boutiques with large-scale national or international systems. Each has a central organization that manages the enterprise, which operates and revises the academic programs and offers schools services for fees. They straddle the public and private sectors: the hub organizations are entirely nongovernmental and funded by private sources, but they serve mostly public schools and systems that are government funded and accountable to legislatures and voters. Being nongovernmental they are somewhat protected from the political pressures with which public schools must cope, as they work with public schools. As mixed organizations IB and AP can raise money for design, development and research, and they can design curricula and certify program quality, things that few school systems have done.

\section{THE INTERSECTION OF SYSTEM WIDE AND NICHE REFORMS}

Though system-wide and niche reforms are different, they are not inconsistent. Each can exist independently or they could operate together. A recent case of the latter is tied to standards-based reform (SBR). The key features of SBR are familiar from Improving America's Schools Act (IASA), No Child Left Behind (NCLB), Race to the Top, and the Common Core. All aimed to reduce educational inequality while improving educational quality. The instruments include demanding academic standards, student assessments keyed to the standards, schools' and educators' accountability for school outcomes, and incentives and support for school improvement. SBR is multi-level as it spans federal, state and local systems, and multi-dimensional as it aims to influence purposes, instruction, leadership and organization. Hence it is different than earlier system-wide reforms which dealt chiefly with single dimensions like access, pedagogy or curriculum.

SBR succeeded in several ways. It acquired elite political support and became the dominant frame for thought and action. It persists, though it shifts shape among states and over time and has encountered serious problems, it shows few sign of evaporating. All states have the key instruments, and each presents these as "aligned," which implies operation on several dimensions of schooling. Nearly all states profess 
commitment to the aims of the reform: strengthen academic quality, improve weak schools and reduce educational inequality. The reform also brought unprecedented attention to educational inequality.

Despite these successes, SBR thus far seems to have not changed teaching and learning systemwide. There are mixed reports but no evidence of system-wide success. One reason is longstanding American skepticism of centralized power; while all states were required to set standards under IASA and NCLB, they could make their own decisions about proficiency standards and cut scores. Most famously, Mississippi set proficiency standards so low that it had very few failing schools, while Massachusetts, which had more demanding criteria of proficiency, had many more failing schools even though its average NAEP test scores were much higher than Mississippi's. These dynamics are becoming clear again as the states deal with the Common Core. Absent broad popular and deep political support for its core aims, many states have not sustained high standards.

Modest effects in practice also are due to the absence of infrastructure that could enable educators to turn the policies into changed teaching and learning. The reforms seem to assume that enclosing school systems in an exostructure of standards, assessments, accountability and help with school improvement will produce change in the schools' endostructure of teaching, learning, and the organization of instruction. Hence SBR does not deploy instruments that could connect exo- and endostructures, including curriculum, teacher education, funds, school and system organization and leadership. System-wide these instruments are either absent or not organized to make the connections. Whether that infrastructure will be created is a large question for SBR. Earlier system-wide reforms succeeded in part because they did not require dramatic change in instruction, but SBR aims to deeply change instruction.

Yet SBR made two successful niche reforms possible: Comprehensive School Reform Designs (CSRD), and high performing charter systems. Each built infrastructure that connected SBR's exostructure with the endostructure of schooling. If SBR has not seen system-wide instructional change, it has been essential to these two niche reforms. 


\section{Comprehensive School Reform Designs}

Several CSRDs created a niche focused on improved teaching and learning in high-poverty schools. ${ }^{32}$ Title I of the 1965 ESEA had attempted such improvement system wide but repeated evaluations reported modest average success at best. The CSRDs aimed to do better with more intensive, focused, and innovative systems. Three of the designs that did well in repeated studies were Core Knowledge (CK), America's Choice (AC), and Success for All (SFA). Each created comprehensive designs, revamping curriculum, instruction, school organization and leadership. They were neither small nor precious: each of the three worked with more schools than exist in many city or state systems. At its peak SFA worked with about 1,500 schools nationally, and now about 1,200 . AC worked with roughly 600 schools nationally, ${ }^{33}$ and last year CK reported intensive work with 1,260 schools nationally, and less intensive work with thousands more. ${ }^{34}$

One source of the niche's success was the incentives to improve high-poverty schools that SBR introduced. Federal legislation helped to create demand for solutions to low-performance in schools that poor children attended, and that opened opportunities to which the CSRs responded. Additionally, the CSRs offered solutions to a problem that many schools, school systems, and public officials wanted to solve-i.e., weak learning for disadvantaged students. Those were long-standing problems but it was only in the late 1980s and early 1990s that pressure and support for better education in high-poverty schools began to materialize.

Support for program development was a third source of the niche's success. The New American Schools Corporation (NAS) and private philanthropies supported the design and development of a small number of promising models of school improvement in the early 1990s. The money and program development NAS brought helped to create a niche that changed the education sector by bringing in outside resources. A fourth source of the niche's success was money for schools to pay for work with the CSRDs. By the 1990s high-poverty elementary schools had relatively large amounts of ESEA Title I funds 
that they could spend to improve instruction school-wide. They could purchase the services and materials that the three CSR's offered.

These things enabled schools to create continuing relationships with the CSRs, to have access to the designers' expertise, assistance with implementation, and much more. That was a fifth source of the niche reform's success: the high-poverty schools that worked with the three CSRs joined systems that shared efforts to dramatically improve teaching and learning. The schools all belonged to existing local districts, but they had another life with the CSR systems. That offered some professional community, for they gave educators access to others who were doing similar work; it helped to build a common vocabulary; it somewhat buffered them from a turbulent environment, and offered the support that can accrue to a sense of shared mission. These were important to creating and sustaining the CSR's niche.

Still another source of the CSRs success was mutual choice: the designers wanted school faculties to decide to work with them only after a large majority of the teachers voted to make the connection, and the designers decided to engage. Like such other niche reforms as Montessori or International Baccalaureate, choice was a way to mobilize mutual commitment to a particular conception of schooling and a vision of what schools should accomplish. The arrangements for choice with the CSRs were far from perfect - in some cases school principals or system managers pushed schools into the work - but mutual choice often did help to create a community that was set off from the larger system and was in certain respects special. Choice of this sort seems inconsistent with system-wide reform, but it has sometimes been orchestrated at the local central system level to operate successfully in sub-systems. ${ }^{35}$

A final source of the niche's success was their mixed organization. The CSRs straddle the publicprivate boundary: they were entirely non-governmental, funded by private sources and operated outside of state and local governments, but the schools and school systems with which they worked were public sector organizations, funded by governments and politically accountable to legislative bodies and voters. This mixed organization enabled the CSRs to raise money, to collect staff to design and develop the 
interventions, to monitor the quality of teaching and management for schools in their system, to support schools as they tried to improve, to provide teacher education and promote communication among schools. The CSRs could mobilize staff and create designs, materials and services that could not have been done by local school systems, yet use these things to improve schools in the public sector. The CSRs could offer services that very few local school systems could perform, especially if they served many students from disadvantaged families.

The mixed organization had some disadvantages. Unlike AP the niche was closely tied to government policies and politics, especially their dependence on Title I ESEA, for Title I is a creature of federal policy and politics. When federal policy changed with NCLB the CSRs had to adapt. ${ }^{36}$ Schools and CSRs in the niche are more vulnerable to political tides than other public-private programs like AP, because funding and legitimacy are tied to government policy and politics. Despite that, the mixed organization created flexibility in operations, funds, and expertise that are rare in public education.

These things added up. SBR's system-wide framework opened ways to create the niche: the three designs addressed the capability problem that plagues system-wide versions of SBR by mobilizing mutual commitment to a vision of the aims of schooling, and by creating infrastructure that connected SBR's goals its key instruments, and work in schools and classrooms. This niche reform would not have been possible without SBR, but SBR could not work very well without the CRSD's resources and infrastructure.

\section{Charter School Systems}

High performing charter systems are the other niche reform that thrived within the SBR frame. Charter schools were initiated and defined by state statutes that made them a distinctive sort of public school. The Clinton, Bush and Obama approaches to standards-based reform (IASA, NCLB and Race to the Top) also legitimized and supported charter schools, for each defined these schools as an element in efforts to improve education for disadvantaged students. The schools have been sustained by parents who support them and press states to authorize more of them, by charter authorizing and management 
organizations that lobby for more schools, by conservative pressure groups that view charter schools as a necessary alternative to conventional schools and lobby to sustain and expand the niche, and by philanthropists of varied political persuasions who press for more charter schools, support lobbyists, or both. Charter schools are deeply embedded in public education: they are state-sponsored, they receive state and local school funds, they receive ESEA Title I monies, and state and local educational authorities regulate them in varying degrees. But they are different than conventional public schools: they use mutual choice to recruit students, some raise much more money than conventional urban systems, and they often avoid much of the regulatory structure of public schooling.

Only a few charter schools measure up to other niche reforms. A majority of the 6,800 schools are stand-alone operations with no connection to any system of schooling. Like other niche reforms they have mutual choice of families and schools, and constituents with power to maintain and expand the niche. Unlike other niche reforms they share no focused academic mission, have no specified clientele, no common curriculum, academic outcomes, or conception of teaching quality, all features that we found with Montessori, IB, the CSRDs, and AP. Instead, most charter schools' missions focus on broad changes in organization: to make schools more responsive to parents, to break the "public schools' monopoly", and to open public education to more innovation. Advocates maintain that these changes would yield academic improvement, though the evidence does not support that claim. ${ }^{37}$

Only a minority of charter schools ( $26 \%$ at last count) belong to a school system - AKA a charter management organization (CMO). ${ }^{38}$ Though stand-alone charter schools must solve pretty much every problem by themselves -- including mission, curriculum, teacher education and evaluation, teacher recruitment and hiring, funds, facilities, student assessment, and more - schools that belong to a CMO may turn to that system for help. But CMOs vary in the extent to which they actually function as systems and help member schools. Some identify their missions generally as academic improvement, innovation and family choice, while others focus more specifically on improved academic performance and educational 
opportunity for students from disadvantaged backgrounds. The latter group, which includes KIPP, Achievement First, Uncommon Schools, and Aspire, shares key attributes with other niche reforms. They embrace specific academic outcomes, for a central aim is to boost students' scores on state tests and thereby improve their chances for further education and fruitful lives. They articulate explicit conceptions of teaching quality that are tied to the academic outcomes. They recruit teachers and managers to these goals, cultivate styles of intense work, and train teachers to perform as the systems intend. Many, but not all, centralize curriculum. All give teachers' detailed ongoing feedback about their teaching. They also manage the environment by defining focused missions, creating common educational infrastructure, using mutual choice to engage students, families, and teachers with the system, and building constituencies that support the niche and advertise its success.

These CMOs present themselves as alternatives to public schools that have badly served poor and minority group children. Independent studies find that students in these schools typically outperform similar students in public schools on state tests. ${ }^{39}$ Not surprisingly, they bring more resources to bear on schools' problem solving than most stand-alone charters or neighboring public schools. ${ }^{40}$ They typically have large waiting lists and attract philanthropic support. Though educational content, organizational culture and pedagogy differs from other niche reforms, the structural features are quite similar.

At the same time, the charter systems have been vigorously criticized. Some see their approach to pedagogy and student compliance as behavioristic and retrogressive (Goodman, 2013). Others see the racial overtones of the schools and their assimilationist messages as neo-colonial (White, 2015). A related critique suggests that while their formal curriculum is preparing students for college, their (not so) hidden curriculum is socializing students to be passive agents rather than critical thinkers (Golann, 2015). These critiques have been amplified by studies that report very high dropout rates, and that even when students matriculate to college they struggle to graduate, ${ }^{41}$ in part because they are unused to the more open environments. ${ }^{42}$ 
These critiques seem warranted, but the CMOs are protected by the niche. They propose a particular kind of bargain: students will work very hard, in ways that to external eyes will look very controlling, teachers' work will be closely guided and controlled, with higher scores on state tests and increased likelihood of college acceptance. More than enough students, parents, teachers, policymakers, and foundations have embraced the bargain to sustain the reform. The fact that many students leave some of the schools, and that there are many parents and critics who do not approve of them, has not disrupted the conditions necessary to sustain the niche. On the contrary, it seems to be growing.

\section{NICHE REFORMS: SUMMARY}

Niche reforms are schooling systems or subsystems that create new space in the education sector by defining a novel and specialized mission, and mobilizing resources to enable pursuit of the mission and a lasting place for the niche. The resources include students, teachers, families, funds and educational programs; these often yield political influence, another important resource. In addition, each reform created a system that might be seen in the corporate world as quality control, but would more appropriately be understood as a means to support systematic learning from experience and the revision of practice based on that learning, something relatively new in the education sector. The Carnegie Foundation for the Advancement of Teaching is in the process of designing such systems under the heading of networked improvement communities. ${ }^{43}$ These niches change the environment by adding to the population of systems and sub-systems and by diversifying organizations, educational missions and programs. ${ }^{44}$

COHERENCE AMID INCOHERENCE:

\section{ISOLATED EXAMPLES OF LOCAL SYSTEMIC REFORMS THAT CHANGE TEACHING AND LEARNING}

Local system-wide reforms that changed teaching and learning exist but appear to be rare. Both the conditions for their success and their paucity are consistent with the ideas we developed above. Two 
of the most successful examples of local system-wide reform of instruction are Long Beach, CA. and Montgomery County, MD. Deft superintendents in each created a coherent reform. Both districts developed standards for students and aligned standards for teachers. Professional development was organized to support teachers learning to teach to the new standards, and principals received training as instructional leaders. Long Beach cultivated a collective identity so that many came to see themselves doing things the "Long Beach Way." That included hiring and promotion from within, particularly seeking senior instructional leaders who had been expert teachers and principals. New ideas were piloted in small ways but only spread district wide with considerable participation and support from teachers. An inclusive political process, a supportive Board, and two very long-running superintendents, Carl Cohn and Chris Steinhauser, kept the reform in place for more than 20 years (Austin et al., 2006; Honan et al., 2004).

In Montgomery County a similarly skilled superintendent, Jerry Weast, was able to develop a widely shared vision organized around a systemic set of solutions anchored in standards. Standards were vertically aligned so that what students and teachers were expected to do at each stage was backward mapped from the standards. An external intermediary, Jon Saphier's group at Research on Better Teaching, helped to organize much of the professional learning. Meanwhile, Weast built relationships with varied stakeholders, creating constructive deals with the local union and publicly advocating for redistributing resources from more to less affluent parts of the district (Childress et al., 2009).

Both districts featured a constellation of attributes that fit with our analysis. The problems that the reformers sought to solve were consistent with demands in the policy environment, which created a problem that teachers needed to solve. The districts provided extensive materials, guidance, and opportunities for professional learning that helped to define what teachers were expected to do and how they were to do it. But they did so in a respectful, collaborative way that gave teachers considerable ownership of the reform. The superintendents brought external stakeholders on board with that vision, enabling an alignment between internal systems and external constituencies. 
Yet such cases seem to be few and far between, and may be difficult to sustain, which also are consistent with our analysis. In each case the superintendents created coherence out of conditions that largely promote incoherence. Skillful leadership enabled them to align systems, develop infrastructure, and build and sustain political support. But if these successes require such skilled leadership, do they provide sustainable models for reforms that move across the entire sector? Many good schools do not outlive the excellent principals who lead them, and the same is likely to be true for districts, even those that present an unusual constellation of supportive conditions.

Would it be possible to change the districts' environment so it would not require such extraordinary leadership to "craft coherence"? Three considerations bear on the answer. The external policy environment does not provide clear and consistent goals, but if the Common Core were politically sustained and effectively implemented it could help. A district-by-district approach to building infrastructure and professional learning would be very complicated, and quite unlike some of the niche reforms described above, where the subsystem operates to bridge jurisdictions. Coalitions of local districts working with NGOs could address this problem, but that could be politically difficult. Finally districts confront diverse political demands. They sometimes reflect legitimate differences in values, and sometimes more narrowly reflect the interests of the claimants, but in either case they impede agreement on common outcomes and infrastructure. Such things are inevitable in democratically governed local schools, but the absence of professional control and the extreme susceptibility to lay influence makes this problem particularly acute in the U.S. Achieving district success thus has been rare. Change in the broader ecosystem that surrounds districts is likely needed for more sector-wide improvement. We turn to that in discussing the Common Core below.

\section{REFORMS WE DID NOT DISCUSS}

The discussion above includes many but not all of the most significant educational reforms in the United States, particularly those related to improving instruction. Most of those that we did not take up 
here would fit with our analysis. For example, the struggles of the Dalton Plan and the niche success of the Coalition of Essential Schools are broadly consistent with our overall argument about progressive education. These and other reforms sought to change the organization and pedagogy of schools considerably, and thus they struggled to scale but succeeded for a time in protected sub-systems. Other reforms, like de-tracking, that were embraced by some reformers but did not address felt needs in schools, have struggled to find broad traction or niche success, absent support from educators or external groups. Desegregation succeeded as long as its political and judicial support held, but receded as political and judicial support waned. Magnet schools are the niche version of system-wide desegregation; these voluntary schools were created and sometimes sustained because they developed support from constituents that was lacking on a wider scale. More research would be needed to investigate these and other cases, but our initial explorations suggest that our analysis holds beyond the reforms that we describe.

\section{CONCLUSION}

One set of final remarks concerns the conditions for the success or failure of reform. A second set concerns how the organization of the education sector shapes reform and its interaction with state school systems. A third concerns how our analysis might inform the Common Core.

\section{Conditions for Success}

Educational reform in the U.S. occurs at the intersection of popular educational ideas and culture, educational knowledge and know-how, and locally operated and popularly governed K-12 schools. Some reforms tried to change instruction in ways that were quite contrary not only to popular educational ideas and norms but also to familiar instructional practices. Successful implementation of such reforms requires more and more unusual educational knowledge and know-how. If such reforms also had no large, broad 
and powerful constituency outside of public education they encountered additional problems. If they were designed for system-wide change they found little success.

System-wide reforms did succeed when they solved problems that educators had, or could easily learn that they had, when they were broadly consistent with the reigning purposes and organization of public education, when implementation did not require deep change in instruction and thus did not require extensive capacity building. Reforms of this sort could gain appreciable support within public education and little opposition within or outside it. Even if some of these conditions were not met, if a reform had broad and deep popular external support it could succeed. The reforms that built our systems of public elementary, secondary and tertiary education succeeded because they had such popular political support. Some required many changes, but popular support carried the day.

A very different sort of reform made significant changes in instruction by defining and creating a niche-a protected and bounded educational and political territory-in which they could thrive and survive. Such niches created environments that included educators and a public that embraced the educational approach, thus buffering them from opposition that would have been likely to arise in the larger school system. They managed the problem of capability by selecting and recruiting motivated and qualified teachers, students and managers, and/or by offering motivated and qualified recruits extensive training. These niche reforms created integrated systems that filled many of the functions lacking elsewhere in public education. Whether they were created by comprehensive school reform designers or a few leadingedge districts, these systems clearly defined a set of educational objectives, created extensive materials, tools, and other forms of practical guidance to support the work, and built sufficient support both within schools and among stakeholders to sustain the reform. ${ }^{45}$

Our discussion might lead some to conclude that to be successful system-wide, reforms must be conservative, in the sense that they do not attempt to push schooling in a direction fundamentally different from the mainstream. But that is not the chief point that we draw from this analysis. For one thing, public 
schools have been increasingly successful in opening access to education; it has been a struggle, but broader access has been a winner. It is true that what many reformers and researchers, including ourselves, have most hoped for-giving each and every student an engaging and intellectually ambitious educationis the most difficult task reformers have attempted, and the one with which they have had the least success in the mainstream. It also is true that reforms which made teachers lives easier, but not necessarily in ways that critics and other observers would support, in particular the differentiation of students through ability grouping and tracking, have been popular and spread quickly. Yet it is also true that more and more niche reforms, public and not, offer some version of counter-cultural and ambitious schooling. We see no reason to suppose that this trend will falter; quite the contrary, we expect it to continue and perhaps to accelerate. Moreover, though some niche reforms increased inequality, others are trying to reduce it.

Our analysis departs from existing accounts in several critical respects. First, there is a view that the school system was developed in the Progressive Era and has not changed much since. We argue instead that there have been successful reforms at both early and more recent periods of American educational history, and that the same factors explain success in both cases. We also point to the way in which the porous nature of schools means that schools have changed considerably as American society and values have changed, particularly liberalization in the treatment of students. Thus while the "grammar" of schooling is quite similar to how it was cast by the administrative progressives, what happens inside that grammar has changed quite considerably. Second, there is a view that instruction never changes, even as reforms are layered onto the periphery of schools. While it is true that classrooms have remained largely teacher-centered (especially in secondary schools), there have been gradual changes in what is taught and how students are treated, in line with changing cultural values. There have also been more substantial pedagogical changes in the various niches that we discussed-AP, IB, Montessori, CSRDs, high performing charters-as well as in a few districts--Montgomery County, Long Beach, District Two in New York Citythat invested heavily in systems to support professional practice. Significant instructional change is possible, 
but it requires an infrastructure and political commitment that have been hard to devise consistently across the system as a whole. Third, there is a view, advanced by Elmore (1996) and others, that changes among groups of volunteers (such as progressive educators) is antithetical to system reform, because it draws the energy of the committed to work in a few schools to the neglect of the many. Charter critics advance a similar argument. We argue, by contrast, that while mutual choice of educators and students is one factor in sustaining niche reforms, these niches also built a considerable infrastructure of materials, assessments, teacher training, and sometimes external examinations, that are critical to their success. Such systems and infrastructure could be crucial to the broader success of reform in the future. We see examples of these subsystems spreading to more and more traditional public schools; that was long true of AP and is increasingly true of IB and Montessori. It may be possible to develop such infrastructure in a niche and then gradually use it to improve the broader public system, or use such things as models for similar efforts.

Some readers may think we presented an unduly sunny picture of reform. One portrait of the American school system is that it: 1) has perpetuated racial and class advantage since its inception, and 2) engenders widespread disengagement from school for many students (rich, poor, and in between), particularly as they get older. We are familiar with the literature that documents these points- From a perspective that evaluates schools as a whole against the hopes of Dewey or Freire, what we have falls very short. Our story is consistent with these realities-it suggests that reforms that would have significantly challenged the distribution of opportunities or fundamentally changed pedagogy have been the hardest to achieve because they have had neither the political support nor the professional infrastructure they would have needed to succeed at scale. Some reasons for this are racism, implicit bias, and segregation, but others are rooted in the organization of the education sector, including the central role of fiscally and economically very unequal local districts, locally operated and popularly governed K-12 schools, the schools' consequent permeability to popular educational ideas and culture, and the 
consequent difficulty of developing broad political support for reforms that would fundamentally alter the distribution of opportunities in the U.S.

At the same time it is mistaken to contend that American schooling is an unbroken string of failures. Reformers erected a large public system in a nation that is allergic to taxes and skeptical of government and they gradually extended access to nearly the entire populace. Schools have been an important path to opportunity for many Americans, including those whom schools initially excluded. Schooling was popular enough to extend upward to make secondary schools commonplace, to extend it downward to incorporate kindergarten, and to spread horizontally to bring a variety of pursuits into schools under the banner of extra-curriculars. Given the evidence that summer learning loss is a more substantial contributor to achievement gaps than schooling, it seems that the very presence of schools is a substantial contributor to reducing socially created inequality among students. It is appropriate to balance critiques with credit for accomplishments.

\section{Organization of the Education Sector}

The configuration of the education sector has a large influence on how reforms are defined and how they are situated in the sector. The public-private divide in the U.S. has kept many reforms that enrich state systems elsewhere from doing so here, and one price of this arrangement has been to somewhat impoverish public schooling. This divide also has tied non-public niche reforms to inequality because chiefly affluent families can afford them. That is a second price of the public-private divide. At the same time, this situation has recently encouraged pressure on public sector niche reforms to do more to include students from minority groups and disadvantaged communities. This configuration is especially significant because of a steady increase in niches and niche reforms. There were very few at the turn of the $20^{\text {th }}$ century, but as the public system grew niche reforms multiplied inside and outside the system. That trend accelerated after WWII, and again around the turn to the $21^{\text {st }}$ century. 
Successful niche reforms vary because the large and loosely-jointed U.S. system of schooling presents several different sorts of opportunities. Some subsist within the public sector-AP and the International Baccalaureate are leading examples-while others like Montessori and Waldorf exist mostly in what Americans define as the private sector. We traced the opportunities to create such niches to four organizational features of the education sector: decentralized and weak governance, school systems' vulnerability to political pressure and opinion, the public-private divide, and the under-professionalization of teaching. These conditions meant that some counter-cultural reforms could thrive without system-wide public support.

The third price of that arrangement, however, has been that public and non-public niche reforms must mobilize their own educational resources. That affects the scale of these reforms, for it has meant that niche reforms had to scale in - to develop their own infrastructure and other resources - in order to exist and then scale up. It makes little sense to estimate scale simply in terms of the quantity of adoptions or replications. One must also consider the extent of infrastructure creation and resource mobilization, for the more ambitious and complex the reform the more infrastructure and related resources must be devised, adapted, and mobilized (Cohen and Ball, 2006). Given the depth of the capability problem and the extent of political and cultural divisions over schooling, we suspect that fundamental change, including in the main stream, is most likely to result from accumulating niche reforms and the capability they bring.

\section{The Common Core}

How do we read our account of creating system-wide improvement in teaching and learning? A pessimistic reading might begin by noting that system-wide reforms were able to succeed only if they did not make significant shifts in the instructional core. An optimistic reading would grant the point but note 
the great advances in access to schooling -- which brought instructional change at least in the sense of opening access to instruction to many hundreds of thousands of children -- that an entire body of system wide reforms accomplished. A pessimistic reading would note that niche reforms succeeded by secluding themselves from public systems, recruiting willing participants, buffering themselves from the environment, and mobilizing many of their own educational resources. The optimistic response might be that this point holds for some niche reforms, but not for IB and AP. They successfully mobilized educational resources within the public system and political support inside and outside that system. Something of that same sort holds for at least two of the CSRDs. Charter schools are a mixed case on that point. From one perspective they pull students, parents and funds away from conventional public schools, perhaps undermining efforts to create system-wide reform. But from another perspective some charter systems brought resources to the public system, not only because they added human and social resources that improve schools but also because they brought funds to school improvement that conventional schools had not. For those reasons some charter systems did a better job of educating disadvantaged students by traditional metrics than conventional schools. But there is increasing evidence that these effective charter systems are exceptions to the more general rule that charters are at best no more effective and in many cases appreciably less effective than comparable public schools.

The optimistic and pessimistic readings are not mutually exclusive. Each flows from our analysis, and together they call attention to several dilemmas that confront this latest and most ambitious reform.

One is political. In our governance system successful system wide reforms must mobilize parents, teachers, and others to create and sustain support for major change in the organization of schooling and instruction. Yet the Common Core is an elite reform that did little to mobilize mass support, and thus opened itself to vigorous opposition: to anything that is nationally "common" on the grounds of states' rights; from parents who are not familiar with the changes in teaching and learning the new standards entail; and by opening the way for some states to label many schools as failing. The Common Core remains 
an elite reform that has accumulated opposition and controversy, yet its success system-wide, like any such reform, depends on sustained mass support. Lacking that it could succeed as a frame for niche reforms where the resources can be mobilized.

A second dilemma is organizational and pedagogical: system-wide change in teaching and learning would require system wide infrastructure to enable change, but there is little of that infrastructure. Unlike No Child Left Behind, the Common Core intends fundamental change, emphasizing depth over breadth and integrating conceptual understanding into more conventional teaching. Like the curriculum reforms of the 1950s and 1960s the Common Core asks teachers to teach in very different ways. Teachers would have to unlearn methods to which they are attached at the same time as they learn very different modes of instruction. Such change would require an extensive infrastructure of coordinated materials, curriculum, teacher training, and professional development, something that has never been created system-wide in the U.S. Such things have been done, but always for sub-systems in protected environments. Could system wide change in instruction be accomplished in a society that has very little experience with such an enterprise? We take up such change a bit further on.

A third dilemma concerns values: The Common Core proposes that instruction be reoriented to common academic standards and outcomes, yet U.S. schools and society are now and always have been deeply divided about the goals and methods of schooling. Each niche reform is built around a specific vision of what good instruction and curriculum are, and what sort of people those systems are to cultivate. Niche reforms succeeded in part because they attract willing adherents to their vision and build the system with those who embrace it. That enabled reformers to build coherent systems of materials, training, and assessment that aligned with the vision. In contrast, successful system-wide reforms either settled on lowest-common denominator visions of schooling (i.e. NCLB's focus on basic reading and math) or they punted the matter to localities, schools, and even classrooms. Is it possible to realize a shared view of 
academic outcomes and instruction amid the diversity of ideas and values to which Americans are attached, often passionately attached?

One way to answer the questions that these dilemmas pose would be for states, LEAs, and education NGOs to cooperate to align their support of the new standards. But if history is any guide the most likely form of such an effort would be alignment at the system level but little investment in building infrastructure to connect system changes to classrooms. Building instructional infrastructure is not something that most government agencies have had much capability to do, and there are no incentives for them to do it across jurisdictions. This approach seems unlikely to succeed, at least as a solo venture.

Another answer would be to encourage existing niche reforms to operate at a larger scale, and to support the development of additional niche reforms under the Common Core umbrella. The CMOs that have considerable evidence of academic success operate only a small number of schools, but they might be able to expand or replicate. AP and IB operate in many more schools, and Montessori seems to have begun to spread into the public sector. Governments and philanthropies could encourage these systems to grow and serve more students, and they could make it easier for the systems to spread across districts or states. If they did grow and spread, foundations could encourage them to develop common methods of teacher education or licensing, common quality assessment for schools, common student assessment, and other instruments that could organize and ground their work. Such an approach would have the advantage of working with rather than against American pluralism by enabling teachers, students, and parents to engage with schools that are consistent with their values and passions. But a potential disadvantage is that like other choice plans they could encourage segregation by class, race or the appetite for formal education. How that turned out would depend partly on how well such niche reforms were monitored and regulated, and that, given the weakness of most governments and continuing disagreement about the ends and means of schooling, probably would require extensive involvement of non-government agencies. ${ }^{46}$ 
Still another way to answer the questions that the three dilemmas pose would be to create or adapt more intermediary organizations that could support public schools' efforts to improve instruction. Their assignment would be to build the professional infrastructure of materials, assessments, and training that would be necessary to consistently develop high quality instruction, and to assist schools as they learned to use these things. They could be funded in part by government, foundations and users' fees, but they would be non-government organizations. There is some precedent for this: the CSRD's were publically and privately sponsored NGOs that worked entirely with high-need public schools. The Common Core could usefully and commonly guide such intermediary organizations. Yet doing these things would require the creation or adaptation of infrastructure, and that is costly and difficult. It also would require recruiting or training expert professionals who had the know-how to help schools improve. Like the other two options it would require lots of money, time, and political support. Some of this would be somewhat less of a challenge for existing intermediaries, like several CSRDs, but it could be more of a challenge for new entrants.

The three approaches are not mutually exclusive: either the second or third, or both could be fruitfully combined with the first. But managing these dilemmas in ways that led to progress on system wide reform would be everything that SBR was thought not to be - incremental, patchy, decentralized and highly variable. Yet in the U.S. system of patchy, decentralized and highly variable governance, this seems to be the most likely path to more common systems. It would take a long time, there would be many mistakes, disappointments, and continuing controversy. Our system of governance was artfully designed to frustrate just such initiatives, and inventing solutions would require a great deal of art, science, craft and persistence.

The challenges are imposing, but it is remarkable that they are discussed now, for some would have been inconceivable in 1986 - just 30 years ago. If the Common Core can be made to develop in ways that take account of the issues we have raised, it could help to make progress toward a less patchy, 
decentralized, highly variable and thus quite unequal organization of public education. The changes that we most desire are the most difficult to accomplish, but for the first time in our history one can see opportunities for progress. 
We wish to thank Larry Cuban, Richard Elmore, Josh Glazer, Pat Graham, Whitney Hegseth, Mike Smith, Jim Spillane and three anonymous reviewers for their perceptive and helpful comments on earlier drafts of this essay.

${ }^{1}$ John Chubb and Terry Moe's 1990s Politics, Markets, and America's Schools (Washington, D.C., Brookings), is a leading case in point; they argue that public schools are paralyzed by democratic politics, and can only become educationally effective if politics is replaced by markets.

${ }^{2}$ The first major study was the RAND Change Agent Studies that Milbrey McLaughlin, Paul Berman and others completed in the 1970s. They did not survey all successful and unsuccessful reforms but probed the circumstances in which a few federal programs did or did not enable local school change. Larry Cuban's (1992) very illuminating essay "Why Some Reforms Last: The Case of the Kindergarten," takes up the broader question more directly. He reviews a host of reforms to schooling that began in the late $19^{\text {th }}$ century, to understand "...the puzzle of how some school reforms survive and get institutionalized and others do not" (p. 166). We return to his analysis throughout, but in his account of kindergarten the reform gained very broad adoption and so changed the organization of schooling and opened access to many students who it benefited, but it had to accommodate to the organization and culture of schooling. This account of success, like Cuban's earlier analysis of teaching in How Teachers Taught, gives a central place to what he earlier called "hybrids" - i.e., blends of traditional and reformist practices and ideas. There are real successes in Cuban's analyses and instruction changes, but the accommodation with extant practices, organizations and ideas always exacts a price.

Just a few years later, in "The "Grammar" of Schooling: Why Has It Been so Hard to Change?" the late David Tyack and William Tobin (1994) ask a different question "Why have the established institutional forms of schooling been so stable and why did most challenges fade or become marginalized?"(p. 453) Their question assumes, unlike Cuban, that reforms have not succeeded. They see the source of the problem in ":...standardized organizational practices in dividing time and space, classifying students and allocating them to classrooms, and splintering knowledge into "subjects," which, they argue, have consistently defeated efforts to make schooling more flexible and humane. The reform failures they seek to explain do not include either changes in instruction, which excludes a very large proportion of educational reforms, or changes in access to schooling, which is the oldest and most central reform tradition. Larry Cuban, in contrast, was centrally concerned with how reforms did or did not influence instruction. A more recent study of these issues is Schneider (2014), which we discuss below in note 45.

${ }^{3}$ We discuss many of the most well-known efforts at reforms, but, in order to provide some depth of analysis, we could not discuss all of them. Further on we briefly consider a few other major reforms and suggest they fit with our analysis. ${ }^{4}$ Two years after the Tyack and Tobin essay was published, Richard Elmore (1996, p. 1) wrote, in an excellent and widely cited essay "Why do good ideas about teaching and learning have so little impact on U.S. education?" This question assumes, contrary to Cuban, that there have been no successful large-scale reforms that affected instruction. His answer is that there is a "systemic incapacity of U.S. schools and the practitioners who work in them, to develop, incorporate and extend new ideas about teaching in anything but a small fraction of schools and classrooms. This incapacity, I argue, is rooted primarily in the incentive structures in which teachers and administrators work." (p. 1) Thus, while Tyack and Tobin locate the impediments to reform in the organizational structure of schooling Elmore locates them in the incentive structures within which teachers and managers work, and he contends that those incentives depend as much on the culture of public education as on its organization.

${ }^{5}$ Richard Elmore put this point succinctly (op. cit.) "The closer an innovation gets to the core of schooling the less likely it will influence teaching and learning on a large scale....innovations that are distant from the core will be more readily adopted on a large scale" (p. 4).

${ }^{6}$ For a very helpful related analysis, see Glazer \& Peurach (2015).

${ }^{7}$ Larry Cuban (op. cit.), lists a large set of innovations that were reforms at the time, many of which have become so integrated into public education that they no longer are recognized as reforms. He writes "The breadth of Progressive school reforms is stunning. By World War I the following innovations had been partially or wholly installed in many city public schools: hot lunches, summer schools, community centers, vocational guidance, industrial education courses, kindergartens, health clinics and school nurses, social workers (or visiting teachers) sex education, 
playgrounds, and organized physical education programs, after school recreation and Americanization programs..." (op. cit., p.168)

${ }^{8}$ Our criteria here are quite similar to those that Larry Cuban used (op. cit.) in his analysis of kindergarten and other reforms.

${ }^{9}$ This is the story that Richard Elmore (op. cit.), tells so well. He writes "...the fundamental problem remains: Attempts to change the stable patterns of the core of schooling....are usually unsuccessful on anything more than a small scale." (p. 3) It isn't clear what "small scale" means in this account, and further on we offer some examples of niche reforms that are not small scale but not system-wide either. Elmore also limited his inquiry to reforms that sought to turn instruction in more humane and engaging directions; access to instruction of any sort (which is an instructional effect of the main stream of system wide reform in the U.S.) does not enter his analysis, nor do other reforms that did spread system wide even though they did not turn instruction in more humane and engaging directions (see note 4 just above).

${ }^{10}$ When he read a draft of this essay, Larry Cuban wrote, "There are other criteria that policy elites have used for the past half-century to determine successful reforms: effectiveness in achieving outcomes consistent with reform ... Of these criteria in judging success, the dominant criterion in use for nearly a half-century is effectiveness of outcomes as measured by test scores, graduation rates, college admissions..." (Personal communication, 1/25/17). These outcome-oriented criteria of success are a relatively recent development, and would not be useful for many of the earlier reforms that we discuss. But they are becoming germane to more recent reforms, and we do recognize them, for example, in our discussion of charter schools. The use of these criteria is part of a change in conceptions of school quality in the U.S, and thus is quite important. But their importance resides largely in their influence - or lack thereof -- on the other criteria of success that we employ: given our analysis of the education sector, scientific and professional determinations are likely to be influential chiefly through the political and social arrangements of that sector, rather than independently.

${ }^{11}$ Here again, our approach is quite similar to Larry Cuban's (op. cit.), and somewhat different than Tyack and Tobin's or Elmore's. Cuban alone defined reforms this broadly, including changes that he probably would have approved of as well as several that he might not have thought well of, while Richard Elmore and David Tyack and William Tobin defined reform only as efforts to turn school organization or instruction in more progressive and humanistic directions - i.e., things they did approve of. That relatively narrow approach limited the reforms they could consider, and thus also the explanations for success and failure that they could entertain. One broader point is that these outstanding researchers, each one a national leader, did not agree on what they meant by reform, even though they were presumably studying the same thing. That made it difficult to develop cumulative knowledge about the issues they consider. We hope to encourage more cumulative work.

12 Katznelson and Weir, op. cit., and Goldin and Katz, op. cit., discuss the economic effects these changes had.

${ }^{13}$ http://nces.ed.gov/pubs93/93442.pdf, p. 27, figure 7. A larger fraction of students attended high school than graduated.

${ }^{14}$ https://nces.ed.gov/naal/lit_history.asp

${ }^{15}$ David Tyack and William Tobin's analysis is consistent with ours. They note the importance of population density as a condition for adoption and the pressure of huge waves of students and unmanageably huge classes in encouraging acceptance of the reform. The ".... graded school had the virtue of being easily reproduced as the population of children mushroomed in cities, no small consideration in the chronically over- crowded urban systems." Later in the same essay, as they explain the failure of efforts to replace graded schools with more flexible reform alternatives like the Dalton Plan, they note that those reforms lacked the public support that graded schools had, because Americans had come to see graded schools as the real thing (Tyack and Tobin, op cit, p. 458-460).

${ }^{16}$ Corporal punishment in schools is still permitted and used in the South, particularly in Alabama, Arkansas, Georgia, Mississippi, and Texas. Worldwide, "as of 2015, most developed countries have abolished the practice, with the exception of some parts of the United States, some Australian states, and Singapore. It is still in common use in a number of countries in Africa and Asia" (https://en.wikipedia.org/wiki/School_corporal_punishment). The use of corporal punishment in schools is thus highly correlated with places where it is common outside of schools, supporting our argument about the porous nature of schools as institutions.

${ }^{17}$ Larry Cuban, personal communication, 1/25/17.

18 David Tyack and William Tobin observed that "Changing basic organizational patterns created considerable cognitive and emotional strain for teachers, for it did not simply add new tasks to familiar routines but also required 
teachers to replace old behavior with new and to persuade pupils, colleagues, parents, and school boards to accept the new patterns as normal and desirable" (Tyack and Tobin, op. cit.,p 478).

${ }^{19}$ James S. Coleman (1961) reported something similar in The Adolescent Society, a dozen years after Elmtown's Youth was first published.

${ }^{20}$ David Tyack and William Tobin (op cit.) made a version of this point in explaining the failure of this reform: "[O]ne reason for the decline of progressive education was that leaders lacked political savvy and fell out of touch with the opinions of school boards and parents. Looking to convince their professional peers, they did not cultivate the kind of broader social movement that might nourish educational and social change. Failure to enlist the support and ideas of the community was especially harmful for fundamental reforms that violated the public's notions of a 'real school,'” Tyack and Tobin, op. cit.,p. 477. When they explain the failure of efforts to overturn graded schools Tyack and Tobin stress the lack of popular support, but they put it as the leaders' failure to mobilize the support. When explaining the success of graded schools they attribute it chiefly to the leaders who desired more rational and hierarchical management. Yet their own evidence shows that graded schools succeeded because they met needs that teachers and others saw as important. For that reason, we are disinclined to suppose that any amount of leadership could have persuaded teachers and parents to mobilize behind alternatives unless they could see that those alternatives would solve real problems that they faced. In fact, the alternatives would have solved problems that the reformers, but not most educators, saw. Solving that problem requires much more than leadership.

${ }^{21}$ Richard Elmore (op. cit.) has an extended and compelling account of this reform, in the course of which he notes several similarities to Progressive education.

${ }^{22}$ Some advanced tracks within public schools and some private schools did make use of the standards and some of the materials which flowed from them, supported largely by sympathetic math departments, parents, and students who were open to a more conceptual approach to math. One study (Green 2014) suggested that this work was also incorporated into many Japanese classrooms. Thus what failed as a systemic approach seems to live on in more supportive niches here and abroad.

${ }^{23}$ These studies were all conducted in the 1990s or later and thus cannot speak to change over time. But they do paint a picture of instruction after the NCTM report, and thus we can use them to evaluate whether the vision of the standards was realized in American classrooms. See Hiebert et al. (2005); Banilower et al. (2013).

${ }^{24}$ https://en.wikipedia.org/wiki/Niche_construction.

${ }^{25} \mathrm{http}: / /$ www.bing.com/search?q=define+bay.

${ }^{26} \mathrm{https}$ ///en.wikipedia.org/wiki/Niche_construction.

${ }^{27}$ For related and helpful analyses, see Glazer and Peurach (2013).

${ }^{28}$ We refer here to Montessori AMI.

${ }^{29} \mathrm{http} / / /$ www.ibo.org/globalassets/publications/ib-research/title1schools-research 2012-2.pdf. Research that one of us (Mehta) is conducting on IB in schools suggests that school-specific knowledge of the program is critical to realizing the values of its design.

${ }^{30} \mathrm{https} / / /$ secure-media.collegeboard.org/digitalServices/pdf/research/2015/2015-Annual-Participation.pdf

${ }^{31}$ https://www.collegeboard.org/releases/2014/class-2013-advanced-placement-results-announced

${ }^{32}$ The below discussion draws heavily on Cohen et al. (2014).

${ }^{33}$ The National Center for Education and the Economy, which sponsored AC, sold it to Pearson, which seems to have dismantled the design.

34 "During the 2013-2014 school year there were 1,260 schools (ranging from preschool through eighth grade) in 46 states and the District of Columbia using all or part of the Core Knowledge Sequence. Thousands more schools use Core Knowledge materials, but the community includes only those schools that send their profile form to the Foundation annually." http://www.coreknowledge.org/about-core-knowledge-schools.

${ }^{35}$ The chief current example is the Small Schools of Choice program in New York City. See Bloom et al. (2010).

${ }^{36}$ For example, NCLB brought a very strict definition of reading programs that schools could adopt, which was inconsistent with SFA's reading program. SFA lost schools and Title I funds as a result, and the effects created significant problems for SFA.

${ }^{37}$ Accordingly, advocates argue that charter schools should be relieved of regulatory burdens that have accumulated around public education, and most state charter laws ease regulations with which conventional public schools must comply. Charter schools need not, for example, employ certified teachers or use state or local salary scales. Advocates also argue that charters should be schools of choice: families must apply and schools must accept students before they 
can enroll, unlike conventional public schools. Charter schools in some states can expel students without due process procedures that many conventional schools require if they expel students.

38 http://www.publiccharters.org/wp-content/uploads/2016/02/New-Closed-2016.pdf

${ }^{39}$ The Center For Research On Educational Outcomes (CREDO) has done national research on charter school outcomes, and published its first study in 2009 (Multiple Choice, Stanford, CA., June 2009). It matched students in charter schools with similar students in local public schools and compared performance. Students' academic growth scores in charter schools were worse than public school students in $37 \%$ of the charter schools. Students' academic growth scores in charter schools were no different than public school students in $48 \%$ of charter schools. Only $17 \%$ of charter schools had stronger student academic growth scores than comparable local public schools. A later CREDO report (National Charter School Study. Stanford University, Stanford, CA., 2013), concluded the "...absolute performance [of charter schools in 2013] seems to be on par with the findings for charters in 2009." (p. 44). But a subsequent report on urban charter schools, where most of the high-performing CMOs are found, reported that urban charters perform at "...a higher average level of performance than the national charter sector as a whole [in 2015]." (CREDO, (2015) Urban Charter School Study: Report on 41 Regions. Center for Research on Education Outcomes, Stanford University, Stanford, CA. http://credo.stanford.edu), [also] ... students in some urban charters outperform matched students in matched local public schools. "Compared to the results found for the national charter sector in...[2013] urban charter schools on average achieve substantially greater levels of growth in math and reading relative to local TPS." (p. 37).

${ }^{40}$ Several independent studies set out the evidence for performance, including Furgeson et al. (2012), Dobbie and Fryer (2011), and Lake et al. (2010).

${ }^{41}$ An internal study published by KIPP in 2011 found that $1 / 3$ of its initial middle school students had graduated from a four-year college within six years of high school graduation. See http://blogs.edweek.org/edweek/inside-schoolresearch/2011/04/kipp_says_one-third_of_its_stu.html

${ }^{42}$ A study by one of us (Mehta, 2017) finds that the schools are now aware of these critiques and are seeking to respond to them, but are hamstrung because their existing structure, processes, and culture need to be undone and unlearned to meet new challenges like instruction in which students are treated as sense-makers, or equipping students with $21^{\text {st }}$ century skills.

43 See https://www.carnegiefoundation.org/resources/publications/getting-ideas-action-building-networkedimprovement-communities-education/.

44 Richard Elmore's proposals for inventing organizations that could solve the problem of "...getting to scale with good educational practice" nicely described some of the resources and educational programs that we discussed here (op. cit., 1996). He wrote that these systems would need to be parallel to, or replace, the main system, and they would need to accomplish certain functions that the regular system was not organized to achieve. To do this would require them to "Develop organizational structures that intensify and focus, rather than dissipate and scatter, intrinsic motivation to engage in challenging practice. Certain types of structures are more likely than others to intensify and focus norms of good practice: organizations in which face-to-face relationships dominate impersonal, bureaucratic ones; organizations in which people routinely interact around common problems of practice; and organizations that focus on the results of their work for students, rather than on the working conditions of professionals. These features can be incorporated into organizations, as well as into the composition of their memberships." (op. cit., pp. 19-20) The organizational structures to which Elmore refers are typical of the niche reforms we discussed.

${ }^{45}$ Our analysis is complementary to Schneider's (2014) recent account of ideas that traveled from the "ivory tower to the schoolhouse." Schneider suggests that four such ideas-Bloom's taxonomy, multiple intelligences, the project method, and direct instruction-have diffused widely across classrooms. In some ways, his argument is similar to ours; in particular, he finds that ideas that stick are philosophically compatible with how teachers think, are easy to implement or add on to existing ways that teachers teach, and are simple enough in their core that they are easily transportable across contexts. These factors are akin to our argument that system wide reforms have been most successful when they solve problems teachers know that they have, or provide a solution for problem once they are alerted to its existence. While Schneider is most interested in what internal characteristics of reforms make them amenable to classroom adoption, our account adds an external lens, by asking about ways in which the broader political economy also heavily shapes which reforms are adopted and which are not. We also consider reforms that would require more significant changes and rethinking of teachers practice, and point to the ways in which district or networks have had to build the systems to support such improvements.

${ }^{46}$ One of us discusses this scenario in more length in Mehta \& Teles (2014). 


\section{$\underline{\text { References }}$}

Anyon, J. (1981). Social class and school knowledge. Curriculum Inquiry, 11(1), 3-42.

Austin, J. et al. (2006). Long Beach Unified District (A): Change that leads to improvement (1992-2002). Cambridge, MA: Public Education Leadership Project at Harvard University.

Banilower, E. R., Smith, P. S., Weiss, I. R., Malzahn, K. A., Campbell, K. M., \& Weis, A. M. (2013). Report of the 2012 national survey of science and mathematics education. Chapel Hill, NC: Horizon Research.

Bloom, H., Thompson, S. R., Y Unterman, R. (2010). Transforming the high school experience. New York: MDRC.

Butchart, R. (2010). Schooling the freed people: Teaching, learning, and the struggle for Black freedom, 1861-1876. Chapel Hill, NC: The University of North Carolina.

Childress, S. et al. (2009). Leading for equity. Cambridge, MA: Harvard Education Press.

Cohen, D.K. (1989). Teaching practice: Plus que ca change.... In P. W. Jackson (Ed.), Contributing to educational change: Perspectives on research and practice (pp. 27-84). Berkeley, CA: McCutchan.

Cohen, D.K. (2011). Teaching and its predicaments. Cambridge, MA: Harvard University Press.

Cohen, D.K. \& Hill, H. (2001). Learning policy: When state education reform works. New Haven, CT: Yale University Press.

Cohen, D.K. \& Moffitt, S. (2009). The ordeal of equality: Did federal regulation fix the schools? Cambridge, MA: Harvard University Press.

Cohen, D.K. et al. (2014). Improvement by design: The promise of better schools. Chicago, IL: University of Chicago Press.

Coleman, J. (1961). The adolescent society. New York, NY: The Free Press of Glencoe.

Cossentino, J. M. (2005). Ritualizing expertise: A non-Montessorian view of the Montessori method. American Journal of Education, 111(2), 211-244

Cossentino, J. M. (2006). Big work: Goodness, vocation, and engagement in the Montessori method. Curriculum Inquiry, 36(1), 63-92.

Cossentino, J. M. (2009). Culture, craft, \& coherence: The unexpected vitality of Montessori teacher training. Journal of Teacher Education, 60(5), 520-527.

Cuban, L. (1984). How teachers taught: Constancy and change in American classrooms, 1890-1990. New York, NY: Teachers College Press.

Cuban, L. (1992). Why some reforms last: The case of the kindergarten. American Journal of Education, 100(2), 166-194 
Dobbie, W. \& Fryer, R. (2011). Getting beneath the veil of effective schools: evidence from New York City. NBER Working Paper 17632. Cambridge, NBER, http://www.nber.org/papers/w17632.

Dow, P. (1991). Schoolhouse politics: Lessons from the Sputnik era. Cambridge, MA: Harvard University Press.

Elmore, R. (1997). "Investing in teacher learning: Staff development and instructional improvement in community school district \#2." Working paper, Harvard University.

Elmore, R. (1996). Getting to scale with good educational practice. Harvard Educational Review, 66(1), 127.

Furgeson, J. et al. 2012. Charter-School Management Organizations: Diverse Strategies and Diverse Student Impacts. Bethell: The University of Washington.

Goldin, Claudia and Larry Katz. (2008). The race between education and technology. Cambridge, MA: Belknap Press of Harvard University Press.

Glazer, J.L. \& Peurach, D.J. (2013). School improvement networks as a strategy for large-scale education reform: The role of educational environments. Educational Policy, 27(4), 676-710

Glazer, J.L. \& Peurach, D.J. (2015). Occupational control in education: The logic and leverage of epistemic communities. Harvard Educational Review, 85(2), 172-202.

Golann, J. (2015). "The paradox of success at a No Excuses school," Sociology of Education, 88(2), 103-119.

Goodman, J. F. (2013). "Charter management organizations and the regulated environment: Is it worth the price?" Educational Researcher, 42(2), 89-96.

Green, E. (2014). Building a better teacher: How teaching works (and how to teach it to everyone). New York, NY: W.W. Norton.

Hiebert, J., Stigler, J., Jacobs, J., Givvin, K., Garnier, H., Smith, M., \& Gallimore, R. (2005). Mathematics teaching in the United States today (and tomorrow): Results from the TIMSS 1999 video study. Educational Evaluation and Policy Analysis, 27(2), 111-132.

Hill, H Litke, E \& Lynch, K. (2017). Learning lessons from instruction: Descriptive results from an observational study of urban elementary classrooms. Working paper, Harvard Graduate School of Education.

Hollingshead, A. (1949). Elmtown's youth. New York, NY: Wiley.

Honan, J. et al. (2004). Long Beach Unified District (B): Working to sustain improvement (2002-2004). Cambridge, MA: Public Education Leadership Project at Harvard University.

Kaestle, C. (1983). Pillars of the republic: Common schools and American society. New York, NY: Hill and Wang. 
Kane, T., \& Staiger, D. (2012). Gathering feedback for teaching: Combining high-quality observations with student surveys and achievement gains. Bill \& Melinda Gates Foundation. Retrieved from www.metproject.org

Katznelson, I. \& Weir, M. (1985). Schooling for all: Class, race, and the decline of the democratic ideal. New York, NY: Basic Books.

Lake, R, Dussault, B, Melissa Bowen, M, Demeritt, A \& Hill, P. (2010). The National Study of Charter Management Organization (CMO) Effectiveness: Report on Interim Findings. Bethell: The University of Washington.

Lortie, D. (1975). Schoolteacher: A sociological study. Chicago, IL: University of Chicago Press.

Lynd, R. S. \& Lynd, H. (1929). Middletown: A study in American culture. New York, NY: Harcourt, Brace \& Company.

Mehta, J. (2013a). The Allure of order: High hopes, dashed expectations and the troubled quest to remake American schooling. New York, NY: Oxford University Press.

Mehta, J. (2013b). "From bureaucracy to profession: Remaking the educational sector for the $21^{\text {st }}$ century." Harvard Educational Review, 83(3). 463-488.

Mehta, J. (2017). "No excuses schooling as a double-edged sword: Control, agency, and the unlearning challenge." Working paper, Harvard Graduate School of Education.

Mehta, J. \& Teles, S. (2014). "Professionalization 2.0: The case for plural professionalism in education." In M. McShane \& F. Hess, Teacher quality 2.0: Will today's reforms hold back tomorrow's schools?, Cambridge, MA: Harvard Education Press.

Mehta, J. \& Fine, S. (2015). "Bringing values back in: How purposes shape practices in coherent school designs." Journal of Educational Change 16(4), 483-510.

Oakes, J. (1985). Keeping track: How schools structure inequality (Second Ed.). New Haven, CT: Yale University Press.

Powell, A., Farrar, E., \& Cohen, D. (1985). The shopping mall high school: Winners and losers in the educational marketplace. New York, NY: Houghton Mifflin.

Rice, J.M. (1893). The public school system of the United States. New York, NY: The Century Co.

Sarason, S. (1971). The culture of the school and the problem of change. Boston, MA: Allyn and Bacon.

Schneider, J. (2014). From the ivory tower to the schoolhouse: How scholarship becomes common knowledge in education. Cambridge, MA: Harvard Education Press.

Stake, R., Easley, J et al. (1978). Case studies in science education. Urbana, IL: Center for Instructional Research and Curriculum Evaluation.

Stevens, R. (1912). The question as a measure of efficiency in instruction. New York City, NY: Teachers College. 
Tyack, D. (1974). The one best system: A history of American urban education. Cambridge, MA: Harvard University Press.

Tyack, D. \& Tobin, W. (1994). The "grammar" of Schooling: Why has it been so hard to change? American Educational Research Journal, 31(3), 453-479.

Tyack, D. \& Hansot, E. (1982). Managers of virtue: Public school leadership in America, 1820-1980. New York, NY: Basic Books.

Welch, W. (1979). Twenty Years of Science Curriculum Development: A Look Back. Review of Research in Education, 7, 282-306

White, T. (2015). Charter schools: Demystifying Whiteness in a market of "no excuses" corporate-styled charter schools. In B. Picower \& E. Mayorga (Eds.), What's race got to do with It? (pp. 121-145). New York, NY: Peter Lang. 